\title{
Challenges for malaria elimination in Brazil
}

Marcelo U. Ferreira ${ }^{* *}$ and Marcia C. Castro ${ }^{2^{*}}$

\begin{abstract}
Brazil currently contributes $42 \%$ of all malaria cases reported in the Latin America and the Caribbean, a region where major progress towards malaria elimination has been achieved in recent years. In 2014, malaria burden in Brazil (143,910 microscopically confirmed cases and 41 malaria-related deaths) has reached its lowest levels in 35 years, Plasmodium falciparum is highly focal, and the geographic boundary of transmission has considerably shrunk. Transmission in Brazil remains entrenched in the Amazon Basin, which accounts for $99.5 \%$ of the country's malaria burden. This paper reviews major lessons learned from past and current malaria control policies in Brazil. A comprehensive discussion of the scientific and logistic challenges that may impact malaria elimination efforts in the country is presented in light of the launching of the Plan for Elimination of Malaria in Brazil in November 2015. Challenges for malaria elimination addressed include the high prevalence of symptomless and submicroscopic infections, emerging anti-malarial drug resistance in P. falciparum and Plasmodium vivax and the lack of safe anti-relapse drugs, the largely neglected burden of malaria in pregnancy, the need for better vector control strategies where Anopheles mosquitoes present a highly variable biting behaviour, human movement, the need for effective surveillance and tools to identify foci of infection in areas with low transmission, and the effects of environmental changes and climatic variability in transmission. Control actions launched in Brazil and results to come are likely to influence control programs in other countries in the Americas.
\end{abstract}

Keywords: Malaria, Malaria control, Malaria elimination, Brazil, Malaria control challenges

\section{Background}

Malaria is endemic to 21 countries in the region of the Americas, with 389,390 laboratory-confirmed cases and 87 malaria-related deaths reported to the Pan American Health Organization (PAHO) in 2014. Nearly $20 \%$ of the local population is exposed to some risk of infection [1]. The region comprises eight of the 34 endemic countries worldwide with a national policy for malaria elimination-namely, Argentina, Costa Rica, El Salvador, Dominican Republic, Mexico, Nicaragua, Panama, and Paraguay [2]; moreover, eighteen of the region's 21 malaria-endemic countries have expressed commitment

\footnotetext{
*Correspondence: muferrei@usp.br; mcastro@hsph.harvard.edu

1 Department of Parasitology, Institute of Biomedical Sciences, University of São Paulo, Av. Prof. Lineu Prestes 1374, Cidade Universitária, São Paulo, SP 05508-900, Brazil

${ }^{2}$ Department of Global Health and Population, Harvard T.H. Chan School of Public Health, 665 Huntington Avenue, Building I, Room 1113, Boston, MA 02115, USA

Full list of author information is available at the end of the article
}

towards malaria elimination. Fourteen malaria-endemic countries in the region are on track to achieve a $75 \%$ reduction in their case incidence rates between 2000 and 2015, as called for by the United Nations' Millennium Development Goals target 6.C [1].

Brazil recorded a $76.8 \%$ decrease in malaria incidence between 2000 and 2014, and now contributes $42 \%$ of all malaria cases reported in the Americas [1]. Transmission remains entrenched in the Amazon Basin, which accounts for $99.5 \%$ of the country's malaria burden. Here, past and current malaria control policies and achievements in Brazil are reviewed, and key scientific and logistic challenges for eliminating residual malaria in the Amazon are discussed.
A brief history of malaria control in Brazil
Malaria control in Brazil started effectively at the beginning of the twentieth century [3]. The first anti- malaria campaign was implemented in 1905, during the 
construction of the port of Santos in the southeastern State of São Paulo, by the well-known physician Carlos Chagas (who few years later described Chagas' disease). An association between housing conditions and the transmission of the disease was soon observed. Mosquito collections inside the houses in the construction area were done every 8 days, screens installed in all windows, and in-house fumigation with sulphur adopted [4-6]. After a month, the daily number of malaria episodes decreased dramatically, with no new cases being observed after 3 months [4]. It was the first time that a measure aimed at killing the adult mosquito was adopted for malaria control [7]. Its success originated the concept that malaria is a 'household infection' (a disease acquired mostly inside the houses), accepted worldwide a few decades later. This concept became the basis for interventions such as indoor residual spraying (IRS) and the use of bed nets.

Between 1923 and 1925, a team led by Mark Boyd analysed four malarious areas in Rio de Janeiro State in order to propose alternatives for malaria control according to their environmental characteristics and the available financial resources [3]. Engineering projects to promote environmental management, such as the construction of drainage systems and filling marshes, led to major reductions in malaria transmission in coastal areas of southeast Brazil in the 1920s and 1930s $[8,9]$.

In 1930, an African malaria vector (originally identified as Anopheles gambiae but later shown to be Anopheles arabiensis [10]) was discovered in the Northeast of Brazil, most likely brought by a ship coming from Senegal, progressively spreading along the coast. In only 8 months in 1938-1939 there were 150,000 cases of malaria, and 14,000 deaths [11]. With the support from the Rockefeller Foundation, a massive control operation was implemented at the end of 1938. Approximately 4000 workers were employed during 19 months of control. The costs of the operation reached US\$1.8 million, $87 \%$ financed by the Brazilian government. Measures of control included monthly house spraying, early case detection and rapid treatment, spraying of cars and trucks leaving or entering the endemic area, elimination of breeding sites, ditching of subsurface water areas, and use of chemical larvicides. In 1940, An arabiensis had been eliminated from Brazil [3, 12]. A similar campaign was repeated in Egypt in 1943-1944 [13]. These two successful campaigns inspired the eradication strategy that marked the World Health Organization (WHO) malaria agenda between 1955 and $1969[14,15]$.

\section{Large-scale malaria control and attempted elimination (1940-1970)}

In the early 1940s, two-thirds of Brazil's 40 million inhabitants lived in malaria-endemic areas. Six to eight million infections, and 80,000 malaria-related deaths, were estimated to occur each year $[16,17]$. At that time, nationwide anti-malarial campaigns were initiated, following the establishment of the National Malaria Service [18]. Large-scale house spraying with dichloro-diphenyltrichloroethane (DDT) started in 1947, after a few pilot studies in Amazonian cities since 1945 [18]. Over the next decade, DDT spraying was extended to two million houses (Fig. 1), with a dramatic effect on malaria transmission. In 1957 , only 250,000 malaria cases were estimated to occur in a population of 62 million [17].

Brazil's malaria map shrank considerably between 1950 and 1970 (Fig. 2). Malaria was virtually eliminated in the Northeastern, Southeastern, and Southern regions of the country, as well as in most of the Center-West region. Malaria elimination efforts initiated in 1958 by the Workgroup for Malaria Control and Eradication were later scaled up by the Malaria Eradication Campaign, officially implemented in 1965 [17], adopting the Global Malaria Eradication Programme strategies of the WHO [19]. First, the DDT house-spraying programme, which had been declining since 1957, was strengthened to reach up to 6.5 million houses in the late 1960s (Fig. 1). During the attack phase, which involved the enactment of anti-larval, insecticidal, and anti-malarial measures for 3-5 years in order to interrupt malaria transmission, all houses in the endemic area should be periodically sprayed with DDT for 3-5 years. Moreover, routine active and passive case detection of febrile cases was implemented, with laboratory diagnosis followed by chloroquine $(\mathrm{CQ})$ treatment and notification of 37,000-110,000 laboratory-confirmed infections each year over the 1960s (Fig. 3).

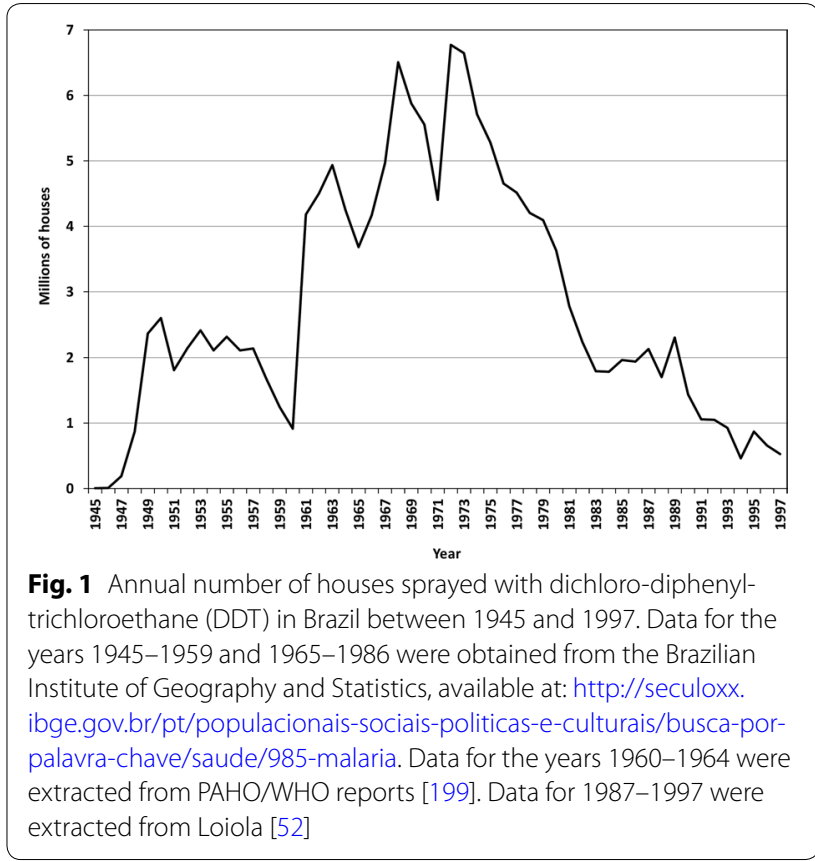




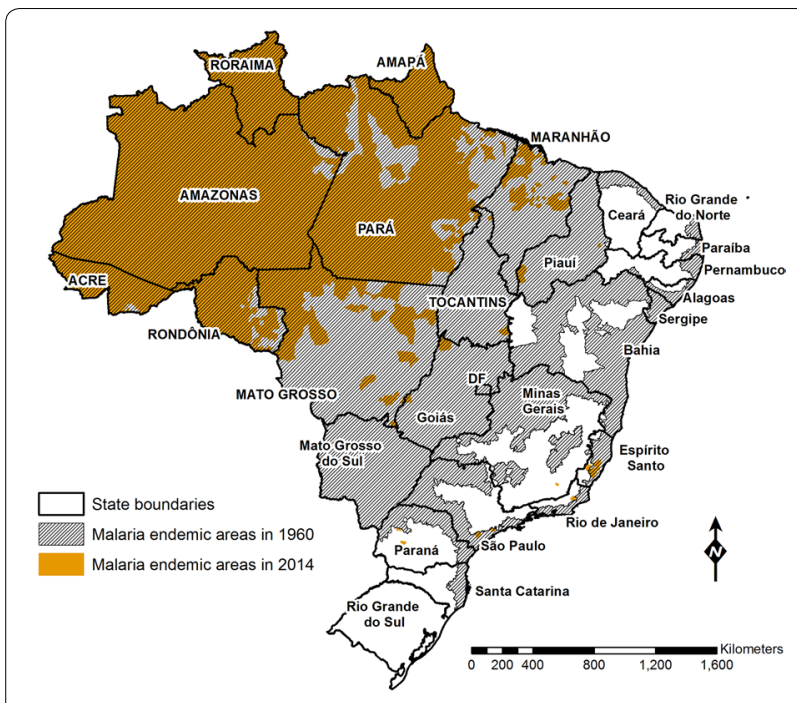

Fig. 2 Extension of the malaria endemic areas in Brazil in 1960 and 2014. The figure shows how the malaria map in Brazil shrunk between 1960 and 2014. Currently, transmission is virtually limited to the

Amazon Basin, an area that covers $60 \%$ of the Brazilian territory and houses $13.4 \%$ of the country's population. States that compose the Amazon region have their names written in uppercase. Data obtained from the National Malaria Prevention and Control Program, Ministry of Health of Brazil

In the 1950s, Brazil pioneered another initiative for malaria control in hard-to-reach populations: the use of CQ added to cooking salt as a chemoprophylaxis strategy (Pinotti's method) [20, 21]. Deployment of CQmedicated or "chloroquinized" salt became a major component of the malaria elimination strategy in Brazil (between 1959 and 1961), as well in Guyana, Tanzania, Ghana, and Indonesia (between 1959 and 1965) [22, 23]. Major concerns regarding this strategy included its effectiveness, the risk of selecting CQ-resistant parasites, and changes in taste and colour of table salt depending on storage conditions [20, 23-25].

The smallest number of malaria cases ever recorded in the country $(36,900)$ was registered in 1961 (Fig. 3). In 1970, 52,469 infections were diagnosed in Brazil, $60 \%$ of them in the Amazon Basin [16]. With $59.7 \%$ of the country's territory, the Amazon had only $4 \%$ of Brazil's 90 million inhabitants enumerated by the 1970 population census. However, the demographic composition of the Amazon started to change at a fast pace, following efforts to integrate the area with the rest of the country, which brought about major increases in malaria transmission [26, 27].

\section{Resurgent malaria on the Amazon frontier (1970-1990)}

Following the implementation of a military dictatorship in Brazil in 1964, political and military factors drove the ideals of national security and integration as part of larger geopolitical strategy [27, 28]. Road construction facilitated the implementation of mining, timber extraction, cattle ranching, and farming settlements in the Amazon. Waves of migrants, mostly from the malariafree South, Southeast and Northeast regions (and thus malaria naïve), responded to federal government incentives: according to the 1980 census, the Amazonian states of Pará, Rondônia, Amazonas, Mato Grosso, Amapá, Acre, and Roraima received nearly one million immigrants during the 1970s [29].

Between 1970 and 1983, one-third of all farming settlements opened by the National Institute for Land Reform (INCRA) in the Amazon were located in the State of Rondônia [30]. While the whole population of the country experienced a yearly growth rate of $2.5 \%$ during the $1970 \mathrm{~s}$, Rondônia registered an astonishing yearly growth rate of $15 \%$, with even higher increases in the rural area [31, 32]. Population growth continued during the 1980s after the Northwest Region Integrated Development Programme (POLONOROESTE), launched in 1981, partly financed by the World Bank [33]. In addition, gold prospecting and mining activities in southern Pará State attracted a flood of migrants, dramatically increasing the population of remote areas with no health infrastructure [29]. As a result, from 1980 to 1991 , the country registered a population growth rate of $1.8 \%$, the states comprising the legal Amazon a rate of $3.25 \%$, and Rondônia's population grew at $7.4 \%$.

The most important impacts of this massive human influx were significant environmental changes due to deforestation, and a dramatic increase in malaria incidence $[29,34]$. With regards to malaria, a new concept of "frontier malaria" was proposed to characterize transmission in the Amazon [26, 35, 36]. Frontier malaria has a temporal pattern that can be summarized in three phases. First, the epidemic phase, marked by intense outbreaks observed for about 3 years after initial settlement. Outbreaks result from a combination of factors that include deforestation, which creates or expands breeding habitats of the main local malaria vector, Anopheles darlingi [37], close to colonists' ramshackle houses in the fringes of the rainforest [38-40], lack of acquired immunity among most of the settlers, precarious habitat conditions that offered no protection against mosquitoes, and lack of adequate knowledge of the disease, among others. Second, the transition phase, characterized by gradual declines in malaria transmission observed over the following years, as the farming settlement becomes consolidated, with less environmental changes, better structured communities, improved housing, and better access to healthcare [35, 41, 42]. Finally, in the endemic phase, malaria transmission reaches lower and stable levels. In this setting, P. falciparum typically predominates in newly opened settlements, being progressively replaced by $P$. vivax in later stages [26]. 


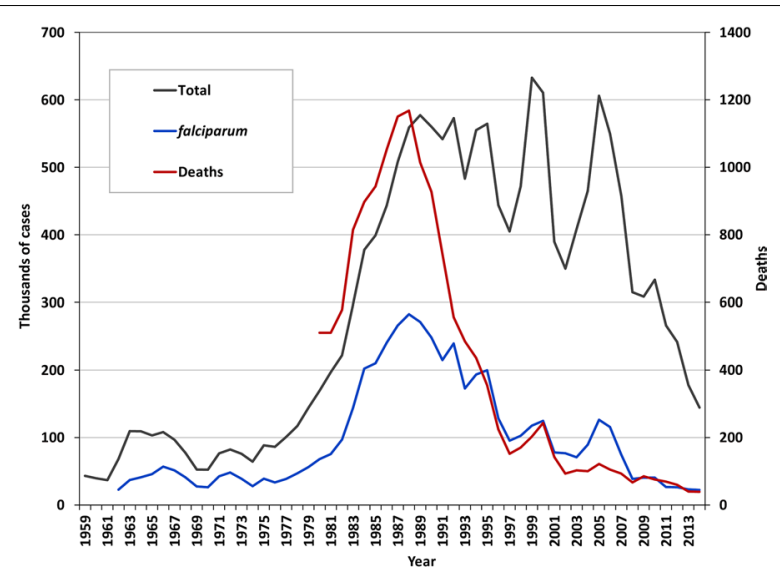

Fig. 3 Annual number of laboratory-confirmed malaria cases reported in Brazil from 1959 to 2014. The total number of cases, those due to Plasmodium falciparum, and the number of malaria-related deaths are shown. Data obtained from the National Malaria Prevention and Control Programme, Ministry of Health of Brazil

In addition to these environmental and demographic changes, the late 1970s and the 1980s were one of the most difficult periods in Brazil's recent economic history. Annual inflation rate was $110 \%$ in 1980, jumping to $1783 \%$ in 1989 . All social indicators deteriorated during this period, including those related to basic health [43]. It was under this scenario that a tenfold increase in malaria incidence was observed between 1970 and 1985; in 1985 two states in the Amazon, Rondônia and Pará, accounted for $73 \%$ of all malaria cases [29]. On average, more than half a million cases were observed annually during the 1990 s, with a peak of 632.8 thousand cases in 1999 .

\section{Changes in malaria species distribution}

Following the concept of frontier malaria, Fig. 3 shows marked temporal changes in the relative contribution of $P$. falciparum to the malaria burden in Brazil. Plasmodium falciparum accounted for $12 \%$ of all malaria infections diagnosed in Brazil in 1961, but this proportion increased over the following years. Between 1966 and 1973, and again between 1983 and 1989, similar proportions of slide-confirmed P. falciparum and P. vivax infections were diagnosed countrywide. Because the transmission of $P$. vivax species maintained an upward trend in the 1990s, while that of $P$. falciparum declined steadily, the proportion of falciparum malaria cases decreased since then. Of note is the fact that malariarelated deaths follow the same pattern as the contribution of falciparum malaria, and the decline in the proportion of falciparum cases was accompanied by a decline in the number of malaria-related deaths (Fig. 3). Plasmodium vivax now causes more than $84 \%$ of all malaria infections diagnosed in Brazil. There is little documented transmission (less than $0.1 \%$ of all cases) of Plasmodium malariae countrywide, although molecular techniques have revealed the presence of this species in 9-12\% of malaria patients in selected settings [44, 45].

The recent predominance of $P$. vivax in Brazil may be partially explained by biologic features that render this species less responsive than $P$. falciparum to control strategies based solely on early diagnosis and prompt treatment of blood-stage infections. First, low-density P. vivax infections are common, especially in areas approaching elimination, making laboratory diagnosis particularly difficult [46]. Second, parasites may persist in human hosts for several months as hypnozoites, the dormant liver stages that may eventually cause relapses [47].

Anti-malarial drugs that target both blood and liver stages are needed for the radical cure of vivax malaria, but primaquine (PQ), the only licensed anti-malarial with hypnozoitocidal activity, requires a relatively long treatment course (7-14 days) and can cause severe hemolysis in patients with glucose-6-phosphate dehydrogenase (G6PD) deficiency [48]. Furthermore, P. vivax transmission is greatly facilitated by the early production of infective stages, mature gametocytes. In fact, most vivax malaria patients have gametocytaemia detected by microscopy by the time they seek treatment [49], and virtually all $P$. vivax infections in Brazil, either symptomatic or asymptomatic, comprise gametocyte-specific pvs 25 gene transcripts detectable with sensitive molecular techniques [50].

\section{Malaria control on the Amazon frontier}

In 1989, the Ministry of Health of Brazil launched the Amazon Basin Malaria Control Programme (PCMAM) to reduce resurgent malaria transmission and prevent its spread to non-endemic areas [51]. PCMAM was in operation until mid-1996, and its main strategy (earlier and more aggressive treatment of malaria cases to reduce transmission and mortality) had a clear shortterm impact. Overall malaria incidence decreased by $60 \%$ between 1989 and 1996, with the proportion of $P$. falciparum infections decreasing from 47 to $29 \%$. The network of malaria diagnosis and treatment outposts was greatly expanded across the Amazon to provide a CQ treatment to all suspected cases until diagnostic test results became available, followed by quinine or mefloquine for slide-confirmed P. falciparum infections [51]. House spraying with DDT, however, had been gradually phased out since the early 1980s [18, 29, 52], and DDT was officially banned from public health use in Brazil in 1998 [53]. Of note is the improvement in the information system that in 1993 gathered data from $98 \%$ of the municipalities considered as having the potential for high malaria risk [51]. 
The gains associated with PCMAM were lost over the next few years, culminating with 637,000 microscopically confirmed malaria cases recorded in 1999 (Fig. 3). As a consequence, in 2000 the Ministry of Health implemented a comprehensive plan to reduce overall malaria incidence, severe morbidity and mortality, to eliminate malaria transmission in the urban area of state capitals across the Amazon, and to prevent resurgence in malaria-free areas. The Intensification Plan of Malaria Control Activities in the Legal Amazon (PIACM) targeted 254 municipalities $(32.1 \%$ of the total number of municipalities in the Amazon), which gathered $93.6 \%$ of the malaria cases. The criteria for selection of those municipalities were: (i) those that had an annual parasite index (API) equal or greater than 50 cases per 1000 people; (ii) those where $P$. falciparum malaria was responsible for $20 \%$ or more of the total number of cases; (iii) the capitals of the nine States that comprise the Amazon region; (iv) the set of municipalities that accounted for at least $80 \%$ of all malaria cases in each State; and (v) those where urban malaria was observed [54]. Control measures were tailored to each specific epidemiological setting. A $39 \%$ reduction in malaria incidence, compared to 1999, was achieved by the end of 2001.

In 2003, the Ministry of Health launched the National Malaria Prevention and Control Programme (NMPCP) with the goal to reduce incidence, mortality and severe malaria cases, to eliminate malaria from urban areas in the state capitals, and to prevent reintroduction of transmission in areas where it had been interrupted [55]. While the goals of the NMPCP were broad, following the decentralization of the health system during the 1990s each municipality could adopt different control strategies. For example, free-of-charge distribution of longlasting insecticide-treated bed nets (LLINs) started in the state of Acre in late 2006 [56], and was later expanded to all high-risk municipalities in the Amazon between 2009 and 2011. In the early twenty first century, countrywide malaria cases, severe morbidity, and lethality have decreased dramatically. In 2000, 615,247 cases were confirmed, with 21,288 hospitalizations and 243 deaths; in 2013 there were 179,236 cases with 2365 hospitalizations and 41 deaths [16].

Currently, the Amazon Basin has nearly 27 million inhabitants (13.4\% of the total population of Brazil). In 2014, 143,910 microscopically confirmed malaria cases and only 41 malaria-related deaths were recorded; this is the lowest incidence in 35 years (Fig. 3). About $60 \%$ of all infections are diagnosed within $48 \mathrm{~h}$ after the onset of symptoms, preventing severe morbidity, and $16 \%$ of the cases were identified through active case detection. Laboratory diagnosis of malaria by microscopy or rapid diagnostic tests (RDTs, which are mostly used in remote areas), is freely provided, being required for free treatment. A network of nearly 3500 malaria outposts, 4900 microscopists and 7900 health agents facilitate access to diagnosis and treatment even in remote communities. First-line treatments, provided at no cost in government-run malaria outposts, are CQ-PQ for $P$. vivax, and an artemisinin combination therapy (ACT) - currently artemether-lumefantrine-plus a gametocidal dose of PQ for P. falciparum. Anti-malarial drugs are not available in the private sector.

Based on those achievements, in November 2015 Brazil was awarded by PAHO the Malaria Champions of the Americas Award. In the same month, the NMCP of the Ministry of Health launched the Plan for Elimination of Malaria in Brazil. The plan is part of the Sustainable Development Goals [57] launched by the United Nations, with the goal to reduce the global number of cases by $90 \%$ until 2030, and to eventually eliminate malaria in 35 countries. The Brazilian plan focuses on P. falciparum malaria, and provides guidelines to municipalities on diagnostics, treatment, vector control, and community sensitization and education $[58,59]$. Next, several potential challenges that may impact the elimination efforts in Brazil are discussed.

\section{Challenges for malaria elimination Symptomless infections}

The natural history of $P$. falciparum malaria has been well characterized in areas of high endemicity in Africa. Children have a primary malaria attack during their first year of life, while most toddlers and juveniles have already developed resistance against severe disease, but still experience a few clinical episodes. African adolescents and adults, in contrast, are often clinically immune; they remain free of malaria symptoms despite continuous exposure to the parasite, but carry parasites throughout the transmission season. Life-long exposure to malaria parasites rarely leads to sterile immunity; low-density blood-stage infections remain detectable with molecular techniques, such as polymerase chain reaction (PCR), in all age groups. Nevertheless, little is known regarding the acquisition of clinical immunity to malaria in areas of less intense malaria transmission in Latin America.

One of the first reports of asymptomatic malaria infections in Brazil came from surveys by Avery-Jones and Ferreira Neto [60] in the costal belt of Santa Catarina State (Southern Region), where P. vivax was the dominant species. In this typical "bromeliad-malaria" setting covered by Atlantic rainforest (see below), the only known malaria vectors were Anopheles (Kerteszia) cruzi and Anopheles (K.) bellator, which breed in water trapped in bromeliad plants [61]. Using conventional microscopy, the investigators found 39 individuals to be parasitaemic 
at one or more monthly house-to-house surveys, but only one of them had a malaria-related illness at the time of diagnosis. Asymptomatic parasite carriage persisted for up to 6 months. Moreover, nine symptomless relapses were diagnosed following CQ treatment of 13 symptomatic infections [60]. Similarly, low-density asymptomatic $P$. vivax infections, some of them initially missed by conventional microscopy but indirectly diagnosed by serology $[62,63]$, have also been reported in other bromeliad-malaria settings in southeast Brazil [16]. Subclinical infections were later described in Amazonians living in traditional riverine communities and exposed to malaria since birth [64-66]. These symptomless infections were found to be four to five times more prevalent than the symptomatic ones in riverine communities in Rondônia, with the risk for developing symptomatic malaria being inversely correlated with the subjects' age [64].

In contrast, all malaria infections, even those with very low parasite densities, were thought to elicit clinical disease in malaria-naïve migrants settled on the Amazon frontier [67-70]. Molecular diagnosis, however, has often revealed entirely symptomless, low-density infections in migrant subjects living in typical frontier settlements in the Amazon [71-73]. For example, $56.6 \%$ of all P. vivax infections diagnosed over 3 years in newly occupied farming settlements in Amazonas State were found to be asymptomatic; one-third of them were both submicroscopic (i.e., missed by microscopy) and asymptomatic [70]. Apparently healthy subjects accounted for half of the total $P$. vivax biomass found in the local population and nearly all asymptomatic $P$. vivax carriers had mature gametocytes detected with molecular techniques. Only $17.0 \%$ of the asymptomatic $P$. vivax carriers developed clinical symptoms over 6 weeks of follow-up, becoming detectable by routine surveillance of febrile illnesses [73]. Similar findings were reported during the follow-up of asymptomatic parasite carriers in another Amazonian settlement [74]. After five to 8 years of continuous exposure to low/moderate levels of malaria transmission, the prevalence or incidence of both infection and malariarelated disease decreased steadily among native Amazonians and migrants, suggesting the acquisition of not only anti-disease immunity but also some degree of antiparasite immunity $[65,73]$.

The infectiousness of gametocytaemia in asymptomatic carriers remains largely unknown. Avery-Jones and Ferreira-Neto [60] suggested that even a small but constantly present number of symptomless individuals could result in a large number of infective man-days. Specifically, if four infective asymptomatic gametocyte carriers were present during all 365 days of the year, a total of 1460 infective man-days would be observed. Similarly, if 10 asymptomatic gametocyte carriers were present during all 365 days of the year, a total of 3650 infective man-days would be observed. However, assuming that individuals would remain infective for 6 days, and considering all 170 laboratory-confirmed symptomatic malaria cases that had been diagnosed over a period of 12 months in their study site in Santa Catarina, only 1020 infective mandays would be observed. Nevertheless, the infectiousness of asymptomatic carriers of low-grade parasitaemia to Amazonian malaria vectors remains understudied; one study described an infection rate of $1.2 \%$ after feeding An. darlingi with blood from asymptomatic $P$. vivax carriers, and of $22 \%$ for the mosquitoes fed with blood from symptomatic carriers [75].

With regards to control activities, the challenge is how to detect asymptomatic infections in order to minimize the number of new infections originating from them. Mass blood surveys can detect asymptomatic malaria, but as transmission declines large populations would have to be screened to diagnose relatively few asymptomatic carriers, reducing the cost-effectiveness of this approach [60]. An alternative is to conduct reactive active case detection so that a confirmed malaria infection triggers the screening of individuals in a defined neighbourhood [76]. Regardless of the detection strategy, the diagnostic techniques available for large-scale use, such as microscopy and RDT, may not be sensitive enough to detect low-grade infections that are typical of residual malaria settings [77].

A reactive active case detection strategy with sensitive molecular diagnostic methods to detect new $P$. vivax infections in the neighbourhood of malaria cases diagnosed by routine surveillance (index cases) is currently being tested in Brazil. This strategy has been tailored for P. vivax infections, which tend to be maintained at low parasite densities and may relapse despite radical treatment. Four case-detection rounds (0, 30, 60 and 180 days after the index case diagnosis) were carried out within a $3 \mathrm{~km}$ radius around the index case to capture individuals during their primary infections and relapses. Molecular barcoding using single-nucleotide polymorphisms (SNPs) [78] or microsatellites [79] will facilitate the analysis of genetic relatedness between patient-derived $P$. vivax samples to elucidate malaria transmission networks.

\section{Eliminating bromeliad malaria in southern Brazil}

A small proportion (about $0.05 \%$ ) of all autochthonous malaria cases currently recorded in Brazil originate from areas along the Serra do Mar mountain range that extends across the states of Rio de Janeiro, Minas Gerais, Espírito Santo, São Paulo, Paraná, and Santa Catarina, in the Southeast and South regions, and is covered with by the Atlantic rainforest biome (Fig. 4) [16]. In these areas, 


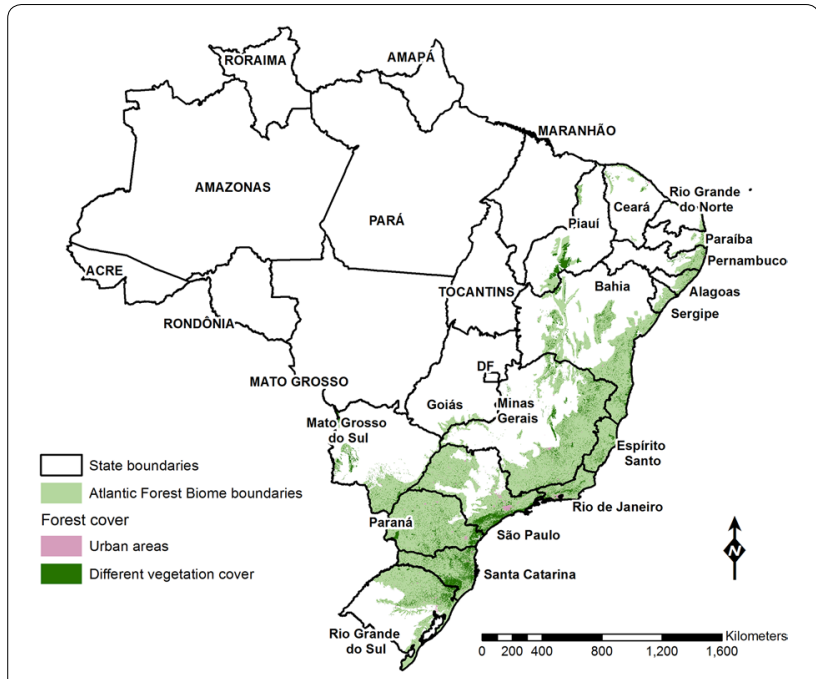

Fig. 4 Area covered by the Atlantic Forest biome in Brazil, where pockets of bromeliad-malaria transmission persist. The extension of the Atlantic forest biome was defined by a federal law in 2006. More than $60 \%$ of the population lives in large urban centers located in the Atlantic forest biome, thus, of the original biome area (which represents $17.4 \%$ of the Brazilian territory), only about $8 \%$ remains as forest. States that compose the Amazon region have their names written in uppercase

the main (or only) malaria vectors are $A n$. cruzi and $A n$. bellator, which breed in water trapped by the leaf axils of bromeliad plants that are particularly abundant in the Atlantic rainforest [61]. Initially called "forest malaria" [80], and later described as "bromeliad malaria" [81, 82], malaria transmitted by Kerteszia anophelines was historically endemic in coastal areas of Southeast and South Brazil [83]. Bromeliad malaria is currently uncommon in most of the Atlantic forest biome of Brazil, but eliminating residual transmission in remaining foci, which involve non-human primates as parasite reservoirs, has been a major challenge for several decades.

Only $P$. vivax and $P$. malariae infections are currently reported in humans in bromeliad malaria settings in Brazil, where monkeys of the genus Alouatta (howler monkeys) and Cebus (capuchin monkeys) are naturally infected with these malaria parasites and may represent major animal reservoirs of parasites [84]. However, $P$. falciparum was nearly as prevalent as $P$. vivax in bromeliad malaria areas of Santa Catarina State in the late 1940s [60]. Furthermore, P. falciparum infection was recently reported in An. cruzi vectors from São Paulo State [85], suggesting that Kerteszia anophelines may also transmit P. falciparum.

Bromeliad malaria constituted a major public health challenge in Santa Catarina, with over 26,000 laboratoryconfirmed infections diagnosed in 1947 in a population of 670,000 [60]. Local transmission of P. falciparum and
P. malariae ceased in 1956 and 1961, respectively, as a result of control activities that included tree removal near major towns and replacement with eucalyptus trees (in which bromeliads do not grow) and vegetable/flowering plants, manual removal of bromeliad plants, intensive DDT spraying, and prompt diagnosis and CQ treatment of laboratory-confirmed infections [86, 87]. Nevertheless, $P$. vivax transmission persisted in the northern coast of Santa Catarina until the mid-1980s, where subpatent and asymptomatic human infections remained relatively common.

Prior to the molecular diagnosis era, serology was used to identify subjects with evidence of current or recent infections in bromeliad malaria foci along the coast of northern Santa Catarina [18]. In 1980-1982, over 20,000 subjects living in endemic sites in the towns of São Francisco do Sul and Araquari had finger-prick blood samples spotted onto filter papers and examined for malarial antibodies with the indirect fluorescent antibody test (IFAT), using $P$. vivax-infected red blood cells as capture antigens. The nearly 500 subjects with antibody titers $\geq 64$, regardless of clinical symptoms, received a full course of CQ and PQ. No further autochthonous malaria cases have been reported in these two towns since 1986 [86]. Similarly, over 11,000 samples were tested for antibodies by IFAT in three consecutive population-based surveys carried out between 1984 and 1984 in rural sites surrounding the town of Peruíbe, southern São Paulo. Overall, $146(1.3 \%)$ samples tested positive (antibody titers $\geq 16)$. The $70(0.6 \%)$ subjects with antibody titers $\geq 64$ were treated with CQ and PQ; 40 infections were further confirmed by thick-smear microscopy [63].

Interestingly, serology has the potential to detect not only ongoing blood-stage infections missed by conventional microscopy [62], but also recent infections, either symptomatic or not, that might have led to $P$. vivax hypnozoite formation in the liver. Despite this potential, the use of serology for targeting asymptomatic carriers of hypnozoites and blood-stage infections in areas approaching $P$. vivax malaria elimination has been rarely reported.

\section{Submicroscopic infections}

Average parasite densities tend to decrease, with higher proportions of $P$. vivax infections being missed by microscopy but detected by PCR as malaria prevalence decreases in Amazonian communities [73]. Accordingly, between half and three-fourths of all PCR-diagnosed infections are typically missed by microscopy in hypoand mesoendemic settings in Brazil $[64,65,72,73]$. Onefourth of all $P$. vivax infections diagnosed in one of these settings had densities $<10$ parasites per microlitre of blood [73], being likely to be missed even by experienced 
microscopists. Similarly, the proportion of P. falciparum infections that are submicroscopic but still detectable by nucleic acid amplification (NAA) increases in Africa, from $20 \%$ in areas with the highest transmission to $70-80 \%$ in areas with the lowest transmission [88].

From a clinical perspective, these chronic, low-density infections may not be entirely harmless. For example, subpatent parasitaemia has been associated with increased risk of anemia in riverine Amazonian populations [65]. From a public health perspective, the most important question is to what extent submicroscopic infections contribute to residual malaria transmission, arguing for the use of more sensitive diagnostic techniques in the context of malaria elimination [89]. In low-prevalence settings in Africa, carriers of a submicroscopic $P$. falciparum parasitaemia were estimated to be the source of $20-50 \%$ of all mosquito infections [88]. However, no comparable estimates are currently available for P. vivax in the Americas. Accordingly, WHO acknowledges the need for "more research to understand better the contribution of submicroscopic infections in malaria transmission in low endemic settings and to identify which diagnostic strategies and NAA-based diagnostic techniques are most cost-effective in accelerating malaria elimination, compared to conventional malaria elimination methods" [89].

Serological tests that detect malaria-specific antibodies are currently unable to differentiate between recent and old infections. Therefore, they play no major role in routine case finding and management. However, in very low transmission settings serology helps to identify subjects who have been recently exposed to $P$. vivax and may still carry hypnozoites or even a low-grade (mostly asymptomatic) asexual blood-stage parasitaemia, that are missed by microscopy $[62,63]$. The bromeliad-malaria elimination campaigns in southern Brazil, as discussed before, illustrate how serology can be useful for targeting human reservoirs of $P$. vivax in areas of residual transmission. Moreover, in communities where malaria has been eliminated, serology may help to identify resurgent malaria, especially when children and young adults, who were born after transmission was interrupted, are found to have specific antibodies.

\section{Evolving Plasmodium falciparum anti-malarial drug resistance}

In 1825, physician José Maria Bomtempo reported that quinine was used indiscriminately and at very high dosages in Rio de Janeiro [90]. Indeed, the first evidence of malaria parasite's resistance to quinine came from Brazil in the early 1900s. Arthur Neiva, in 1907, diagnosed malaria infections in individuals under compulsory prophylaxis with quinine (500 $\mathrm{mg}$ every 2 or 3 days) who worked in highly malarious marshlands $60 \mathrm{~km}$ away from Rio de Janeiro, the country's capital at that time [91]. He thus recommended daily $500 \mathrm{mg}$ doses of quinine as the only effective chemoprophylaxis in that area [91]. Miguel Couto [92] reported the use of intravenous methylene blue to treat quinine-resistant malaria infections acquired in Rio de Janeiro as well as in the Amazon, but he did not describe the quinine dose initially used. The finding by Oswaldo Cruz of quinine-resistant malaria among workers in the Madeira-Mamoré railway construction site located in Rondônia state, western Amazon [93], was soon confirmed by Bernhard Nocht and Heinrich Werner, who documented quinine failures during the treatment of German workers returning from that region to Hamburg in 1910 [94]. Interestingly, despite these early reports, quinine remained widely used in Brazil until the mid-1990s, usually in association with tetracycline or doxycycline, to treat uncomplicated $P$. falciparum infections. Relatively little evidence of in vitro $[95,96]$ or in vivo resistance to quinine $[97,98]$ has been published since then.

Emerging resistance to $\mathrm{CQ}$ and a fixed-dose sulfadoxine-pyrimethamine (SP) combination may have greatly contributed to explosive $P$. falciparum malaria outbreaks across the Amazon in the 1980s. The first report of CQ failure to clear P. falciparum infections in Brazil, presented at a national medical conference in 1954, drew relatively little attention [99], but later publications documented CQ resistance in Brazil $[100,101]$ and Colombia [102] in the early 1960s. At least two CQ-resistant founder populations have been identified in this region, one circulating in the Amazon Basin of Brazil and Peru, and the second in Ecuador and Colombia [103]. CQ resistance became widespread across the Amazon Basin by the mid-1980s [104], when malaria cases were on the rise associated with colonization projects and environmental changes in the region (Fig. 3).

SP had been available in Brazil since the 1960s to treat CQ-resistant falciparum malaria [105]. SP-resistant $P$. falciparum strains emerged within a few years, being first documented in the Centre-West region in 1972 [106]. By the end of the 1980s, SP failed to cure $>90 \%$ of $P$. falciparum infections in the Amazon [99], and since 1990, SP is no longer recommended for malaria chemotherapy in Brazil [99]. Before the introduction of ACT in 2006 [107], the first-line regimens for uncomplicated falciparum malaria recommended by the Ministry of Health of Brazil were quinine plus doxycycline (formerly tetracycline) for 7 days or a single dose of mefloquine. Case reports of mefloquine (e.g., [108]) and quinine-tetracycline [e.g., 109] failure in falciparum malaria have been published since then. The few clinical trials that evaluated the therapeutic efficacy of these regimens reported cure rates 
ranging between 98.9 [110] and $100 \%$ [111] for mefloquine, and between 77.3 [98] and $100 \%$ [97] for quinine plus tetracycline.

ACT has gradually replaced quinine-doxycycline and mefloquine as the first-line regimen for uncomplicated falciparum malaria in Brazil in the late 2000s. Nearly 24,000 P. falciparum infections were treated with a fixeddose artesunate-mefloquine (ASMQ) combination in Juruá Valley, Acre, between July 2006 and December 2008. Following this large-scale intervention, $P$. falciparum malaria incidence rates decreased substantially, with lower hospital admission rates, and a reduced proportion of $P$. falciparum to $P$. vivax infections in this region [112]. A recently completed trial showed no evidence, either clinical or molecular, for emerging $P$. falciparum resistance to the fixed-dose ASMQ combination in Juruá Valley [113]. More data on ACT efficacy in other areas of Brazil are expected to be made publicly available by the Amazon Network for the Surveillance of Antimalarial Drug Resistance (RAVREDA), a network organized in 2001 by the Amazonian countries of South America, with PAHO support, to respond to the challenge of antimalarial drug resistance in the region. RAVREDA operates in close association with the Amazonian Malaria Initiative (AMI), a partnership of the United States Agency for International Development with PAHO, the Centers for Disease Control and Prevention (CDC), the Management Sciences for Health's Rational Pharmaceutical Management Plus (MSH/RPM Plus) programme, the United States Pharmacopoeia, and Links Media, Inc.

Resistance to artemisinin derivatives has not been documented in Brazil, but there is some concern that resistant parasites may circulate in areas of Suriname, Guyana and French Guyana bordering Brazil. Suriname has recently attracted a large number of immigrants, mainly from Brazil, to work in gold mines in the eastern and central parts of the country. An estimated 15,000 (mostly illegal) miners currently live in settlements where health infrastructure and compliance with national malaria treatment policies are typically very poor [114]. A recent study in Suriname has documented a large proportion (31 \%) of P. falciparum-infected patients treated with artemether-lumefantrine who remained parasitaemic by day 3 , consistent with some degree of artemether resistance in Suriname [115], although these findings have not been confirmed in other areas of the country. Nevertheless, Suriname is complying with WHO recommendations for malaria control and P. falciparum malaria is now rarely diagnosed in the country [116]. In Guyana, the kelch propeller domain ( $k 13)$ gene mutation C580Y, associated with artemisinin resistance, has been found in $5 \%$ of 98 P. falciparum isolates analysed [117]. Interestingly, an analysis of polymorphisms upstream and downstream the $k 13$ gene suggest that the C580Y mutation has emerged independently in Guyana and Southeast Asia [117]; these mutant parasites, however, did not have their drug sensitivity patterns analyzed so far. In French Guyana, up to 15,000 illegal gold prospectors live in high-endemic areas along with 30,000 legal residents. They typically use erratic ACT-based regimens, potentially including fake or substandard drugs, to treat P. falciparum infections, favouring the selection of drugresistant strains. Artemisinin resistance had not been characterized so far in French Guyana, but the country fails to comply with WHO recommendations for antimalarial treatment [116]. Therefore, unequal cross-border efforts to control malaria and contain the emergence of anti-malarial drug resistance pose potential threats to eliminate the disease from French Guyana, Brazil and Suriname [116].

\section{Plasmodium vivax resistance to chloroquine}

The global spread of CQ-resistant P. vivax strains [118] can further complicate malaria elimination efforts in Brazil. Radical cure of $P$. vivax malaria is achieved with $25 \mathrm{mg} / \mathrm{kg}$ of CQ base over 3 days (maximum adult dose, 1.5 g over 3 days), combined with a short hypnozoitocidal regimen of $0.5 \mathrm{mg} / \mathrm{kg} /$ day of PQ base (maximum daily dose, $30 \mathrm{mg}$ /day) over 7 days in patients that weight under $70 \mathrm{~kg}$. Since subtherapeutic PQ doses may lead to relapses in overweight patients [119], weight-adjusted PQ doses are now recommended in Brazil for patients over $70 \mathrm{~kg}[120]$.

CQ-resistant vivax malaria has been reported in Colombia and Brazil since in the late 1980s, but antimalarial treatment had not been supervised, and drug levels were not measured, in these early studies [reviewed by 121]. The first solid evidence of CQ-resistant $P$. vivax infections in South America was published in 1996. Two Canadian patients returning from Guyana had received $\mathrm{CQ}$ and $\mathrm{PQ}$, with therapeutic CQ levels documented at the time of parasite recurrence [122]. Further evidence of $P$. vivax resistance, confirmed by CQ level measurements, originated from patients from Peru given CQ alone in 2003 [123]. Two studies described $P$. vivax resistance to CQ in Manaus, the major port city in the Amazon Basin of Brazil, in the 2000s. The first study documented $P$. vivax recrudescence, despite adequate plasma levels of CQ, in 11 of 109 (10.1\%) patients treated with CQ alone who were followed up for 28 days [124]. The second study reported $P$. vivax recurrences in seven of 135 (5.2\%) patients treated with $\mathrm{CQ}$ and $\mathrm{PQ}$ who were followed up for 28 days; all of them had CQ levels above $100 \mathrm{ng} /$ $\mathrm{mL}$ of whole blood at the time of recurrence [125]. It remains to be determined whether CQ resistance has spread to other areas in Brazil; a very recent clinical trial 
has detected little $P$. vivax resistance to CQ alone (2\%), and none to CQ-PQ combination, in major malaria hotspots in Juruá Valley (MUF, unpublished observations). Although ACT has been used to treat CQ-resistant $P$. vivax infections worldwide [126], its efficacy as an alternative to $C Q$ remains unknown in Brazil.

The finding that PQ reverses CQ resistance in $P$. falciparum suggests that a similar effect might occur in $P$. vivax isolates simultaneously exposed to both drugs [reviewed by 127]. In fact, recent meta-analyses showed a lower efficacy of CQ alone against $P$. vivax asexual blood stages compared to CQ co-administered with PQ $[118,128]$. Over the past 60 years, CQ and PQ have been routinely combined for the radical cure of $P$. vivax infections in most of South America, but not in Melanesia and Southeast Asia, where highly prevalent severe G6PD deficiency may lead to PQ-induced haemolysis. Indeed, CQ-resistant $P$. vivax emerged in regions where $\mathrm{PQ}$ is not widely used and remains less common in countries where CQ and PQ are routinely coadministered [118, 121], indicating that $\mathrm{CQ}-\mathrm{PQ}$ combination therapy may have delayed the emergence of CQ-resistant $P$. vivax strains in selected settings.

PQ safety is an open question, since there is no practical, field-deployable rapid diagnosis test for G6PD deficiency screening prior to PQ administration [129]. Severe G6PD deficiency is uncommon across the Amazon Basin [130, 131], but severe haemolysis has been occasionally reported following PQ treatment [132]. Moreover, PQ cannot be administered to pregnant and breastfeeding women and to children less than 6 months of age, because the risk of haemolysis. PQ efficacy also remains largely undetermined in Brazil. Relapse rates between 14.0 and $24.5 \%$ have been described following supervised CQ-PQ treatment of imported P. vivax infections in non-endemic sites $[119,133]$. Furthermore, an imported $P$. vivax infection acquired in Brazil was found to relapse despite the administration of $900 \mathrm{mg}$ of PQ over 30 days [134]. The extent to which PQ metabolism in Amazonian populations is affected by polymorphisms in cytochrome P450 (CYP) family members, such as CYP 2D6, remains unknown. In fact, reported failures of PQ may be partially associated with poor PQ metabolism in patients, rather than true drug resistance. However, the local monkey-adapted P. vivax strain Brazil I is PQresistant in monkeys [135]. If PQ is failing in Brazil, for whatever reason, a substantial proportion of $P$. vivax infections may actually be relapses, placing improved anti-relapse treatment as a top research priority for guiding malaria elimination in this country.

The finding that high-dose PQ regimens are safe and effective among G6PD-normal subjects led the US Centers for Disease Control and Prevention (CDC) to recommend $420 \mathrm{mg}$ of PQ over 14 days as the standard anti-relapse regimen for adults in areas where standard PQ treatment fails [136]. WHO recommends a PQ dose of $0.5 \mathrm{mg} / \mathrm{kg}$ of body weight over 14 days to prevent relapses of infections acquired in Southeast Asia and Oceania [137], but this high-dose PQ regimen has not been evaluated in Brazil. Tafenoquine (TQ) is an alternative to $\mathrm{PQ}$ that requires shorter treatment regimens with improved compliance; a single dose of $300 \mathrm{mg}$ TQ coadministered with $\mathrm{CQ}$ is effective to prevent $P$. vivax relapses in Brazil, Peru, India, and Thailand [138]. However, treatment with this long-lasting hypnozoitocidal drug does require prior screening for G6PD deficiency, an additional challenge due to the lack of a rapid screening test. Moreover, TQ is neither licensed nor available commercially in Brazil.

\section{The hidden burden of malaria in pregnancy}

Malaria infection during pregnancy is associated with substantial risks for the mother, her fetus, and the neonate. Stillbirth, intrauterine growth retardation, prematurity, low birth weight, spontaneous abortion, increased neonatal and maternal mortality, and reduced neurocognitive function later in childhood are documented complications of malaria in pregnancy (MiP) $[139,140]$.

Between 6000 and 9000 microscopy-confirmed MiP cases are recorded in Brazil each year [141]. This represents $4-6 \%$ of all malaria cases in the country. However, since conventional microscopy and RDTs fail to detect a substantial proportion of MiP episodes that are later diagnosed by PCR [142], these figures are likely to be underestimated. Health professionals involved in antenatal care, such as nurses and obstetricians, usually do not perceive MiP as a major preventable and treatable cause of morbidity in pregnant women and their offspring. This is partially due to the fact that infections with $P$. vivax are associated with less severe clinical consequences in pregnant women than those with $P$. falciparum, although an increased risk of low birth weight and anemia was documented in a large cohort study in Southeast Asia [143]. Erythrocytes parasitized with the former species do not sequester massively in placental capillaries [144, 145], but some placental changes associated with MiP, such as syncytial knotting and increased thickness of the placental barrier, have been recently documented in Brazil and may affect fetal growth $[145,146]$. Because PQ cannot be administered during pregnancy, relapses are common. Overall compliance with a weekly CQ regimen for suppressing relapses following $P$. vivax infection during pregnancy is usually poor in endemic areas of Brazil.

Almost one-third of the MiP cases recorded in Brazil between 2003 and 2012 were due to P. falciparum, although this species accounted for only one-fourth of 
the malaria burden in non-pregnant women during the same period [141]. Indeed, a cross-sectional survey of 1699 febrile women at childbearing age found a significantly greater $P$. falciparum to $P$. vivax ratio in pregnant women (1:2.3) than in their non-pregnant counterparts (1:5.6) living in Manaus, Brazil [147]. Also, a cohort study in the Peruvian Amazon found pregnant women to be twice more likely to have $P$. falciparum infections than non-pregnant women living in the same community, but no pregnancy-associated difference was found in the risk of $P$. vivax infections [148].

Pregnant women living in malaria-endemic areas of Brazil must be tested for malaria parasites at every antenatal care visit and receive supervised anti-malarial treatment whenever MiP is confirmed [141]. In areas with stable transmission of $P$. falciparum in Africa, pregnant women are encouraged to sleep under insecticide treated bed nets (ITNs), and at least two doses of intermittent preventive treatment (IPTp) with SP should be administered during antenatal care visits to prevent MiP [149]. Although sub-Saharan Africa has high rates of antenatal care attendance, current IPTp coverage is still low [150], despite the fact that IPTp-SP is highly cost-effective for prevention of $\mathrm{MiP}$ and reduction of neonatal mortality, even in areas with some molecular evidence of SP resistance in P. falciparum populations [151]. Currently, there is no evidence to support the use of IPTp-SP to prevent $\mathrm{MiP}$ in areas with substantially lower levels of malaria transmission, such as those in Brazil.

\section{Vector behaviour and control}

Research conducted in the Amazon in 1931 showed that An. darlingi was found in much greater numbers indoors (endophilic) than outdoors (exophilic). Data collected between July 1942 and June 1946 in Rondônia (then called Guaporé territory) indicated that $93 \%$ of the mosquitoes captured were present inside the houses. For the whole Amazon, this percentage was $88 \%$ [152]. In 1977, another study showed that An. darlingi would enter houses that had been sprayed with DDT, but only to feed, and not to rest, as they would do in unsprayed houses [153]. Early records also show that An. darlingi was to some extent exophilic before the use of DDT [154]. Studies in Rondônia during the 1980s, however, found An. darlingi mainly outdoors, in the vicinity of houses [69, 153, 155, 156]. In addition to differences in biting location, $A n$. darlingi also shows different patterns of peak biting time. For example, bimodal biting curves have been reported, with peaks in the early evening and at dawn, hours at which workers could be carrying out outdoor activities [156-158].

The exophilic behaviour is a point of discussion. Some argue that DDT use could have contributed to this transformation, selecting the exophilic strains to be more prevalent. Others consider that extensive deforestation and disorganized occupation could be indirectly responsible for modifications in the mosquito behaviour, subtracting its former sources of food (wild animals, who were scared away by the new settlers) and bringing man closer to its breeding places [3]. Population and mutation differences have been documented in South America (where An. darlingi is the dominant vector), with a marked north-south divide [159]. Although chromosomal and isoenzymatic studies show a high degree of heterogeneity, no morphological characteristics for separation of sub-species have been found [156].

This diversity in An. darlingi behaviour has important implications for vector control. First, an exophilic behaviour and peak biting times limit the impact that using ITNs could have in malaria transmission. Despite the evidence on ITN effectiveness [160], no large scale trial of bed nets have been conducted in the Amazon. However, there is evidence that targeting ITNs to specific areas based on vector behaviour can be an important strategy to add to a package of interventions to reduce malaria transmission. Two studies conducted in specific areas in Venezuela and Colombia showed efficacy in ITNs to reduce malaria risk [161, 162]. In Brazil, LLINs impregnated with permethrin were distributed across Juruá Valley (see Fig. 4) starting in late-2006 [163]. Although malaria incidence fell by $32 \%$ over the next months, the intervention did not follow a systematic design to allow a proper impact evaluation, controlling for other ongoing interventions. Also, two additional rounds of LLIN distribution $(2010,2014)$ led to little changes in malaria rates. Second, with regard to IRS, limiting factors include An. darlingi behaviour and the quality of houses, particularly in rural areas-these are often made with poor construction materials, with partial walls and no windows [56]. Although IRS was largely used in Brazil starting in the mid-1940s, during the first elimination campaign (Fig. 1), currently it is restricted to areas that match certain technical and operational requirements defined by the Ministry of Health [164]. Third, the use of larvicides is restricted to specific water habitats that can be easily identified and reached, such as fish ponds [165].

In summary, vector ecology and behaviour coupled with the local environmental conditions in the Amazon bring about major barriers for the adoption of large-scale vector control strategies. Indeed, in 2014, about $3 \%$ of the population in the Amazon was covered by treated nets, and $1 \%$ covered by IRS [166]. Yet, targeted interventions should be considered as important additions to a range of control strategies to reduce malaria transmission, as long as decisions are based on local knowledge of vector behaviour. 


\section{Hitting foci of Plasmodium falciparum infection}

Approximately 20,000 P. falciparum malaria cases were recorded in the Amazon Basin of Brazil in 2014. They were mostly restricted to ten high-risk areas, which account for three-fourths of the cases recorded countrywide (Fig. 5). Four municipalities in Juruá Valley (in the Western portion of the Amazon, close to the border with Peru), with a combined population of nearly 120,000 inhabitants, reported $46 \%$ of all P. falciparum infections diagnosed in Brazil in 2014. The highly focal nature of $P$. falciparum malaria indicates that eliminating transmission of this species may be technically feasible by targeting a limited number of transmission pockets. Moreover, the potential of falciparum malaria for high morbidity and mortality and multidrug resistance, as well as its comparatively greater susceptibility to existing control measures, provide compelling arguments for prioritizing this species in malaria elimination strategies in Brazil. Indeed, the recently launched Plan for Elimination of Malaria in Brazil devotes special attention to P. falciparum malaria, and has the ultimate goal of eliminating the disease by 2030 [167].

As argued for the Greater Mekong Subregion in Asia [168], the window of opportunity for P. falciparum elimination may be rather short. First, an elimination strategy must be implemented before widespread anti-malarial drug resistance (more specifically, resistance to artemisinin derivatives) makes $P$. falciparum infections in

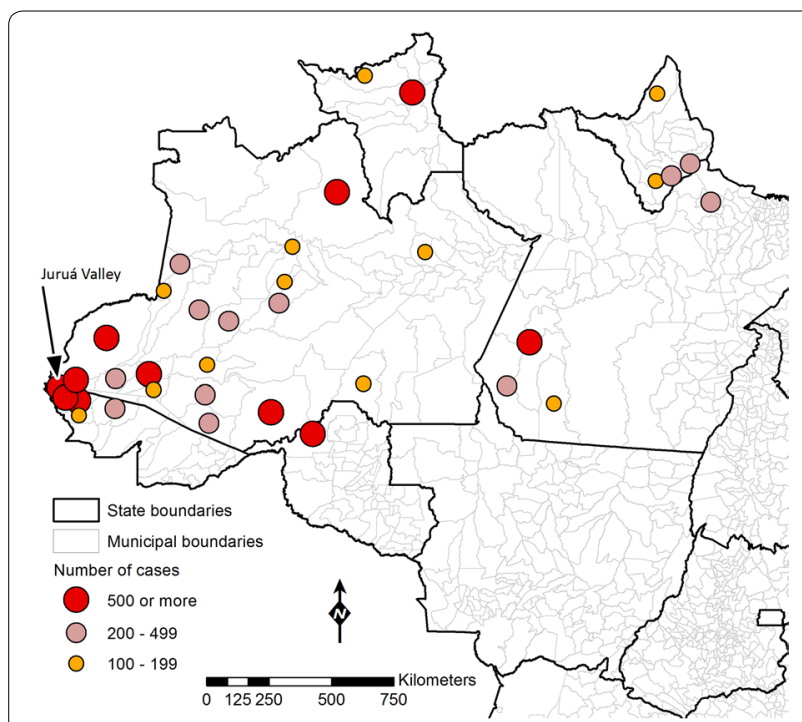

Fig. 5 Current Plasmodium falciparum foci in Brazil. Municipalities indicated with circles in the map accounted for about $75 \%$ of the laboratory-confirmed P. falciparum infections recorded in the Amazon in 2014. The circle sizes are proportional to the absolute number of cases in each municipality. Four high-risk municipalities (Cruzeiro do Sul, Mâncio Lima, Rodrigues Alves, and Guajará) are situated in Juruá Valley, westernmost Brazil, close to the border with Peru
Brazil untreatable with currently available drugs. In other words, "multidrug resistance is both an impediment to elimination and a reason for pursuing it" [168]. Second, financing and political commitment to malaria elimination tends to wave once $P$. falciparum becomes widely perceived as a relatively minor public health problem and other competing priorities emerge countrywide.

Eliminating residual $P$. falciparum transmission will require a comprehensive assessment of the factors that favor malaria transmission in well-defined foci across the Amazon. Improved local knowledge regarding the relative contribution of vectors (e.g., species distribution, abundance, behaviour, and insecticide resistance), parasites (e.g., drug resistance and virulence), humans (e.g., behaviour, health infrastructure, and patterns of mobility), and the environment (e.g., land use and land change) to persisting $P$. falciparum transmission will be crucial, especially since underlying drivers of transmission are not likely to be same across foci. Indeed, human-made vector breeding sites (e.g., fish pounds opened for commercial aquaculture) are a major factor leading to the current increase in P. falciparum malaria incidence in urban and peri-urban areas of Juruá Valley (Acre State, Western Amazon). Mining activities favor transmission in the outskirts of Itaituba (Pará State, Eastern Amazon), while in Barcelos (northern Amazonas State, Western Amazon) the majority of malaria cases is recorded in remote protected areas (mostly indigenous reserves). Finally, the main endemic sites in Lábrea (southern Amazonas State) are newly opened farming settlements. Thus, different strategies will be needed for controlling and eventually eliminating $P$. falciparum in each area.

At present, there is no evidence that artemisinin-resistant $P$. falciparum strains have been imported into Brazil. No data are available on anti-malarial drug resistance patterns of $P$. falciparum infecting Brazilians returning from mining camps in the Guiana Shield (a region comprising Guyana, French Guiana, Suriname and parts of Colombia, Venezuela and the northernmost tip of Brazil), where artemisinin resistance is suspected to be emerging [115].

\section{Environmental changes}

The natural environmental characteristics of the Amazon Basin offer suitable conditions for malaria transmission: temperature, humidity and the local vegetation guarantee a large population of vectors year-round, with less seasonal variation when compared to other areas [26]. Also, the water level of rivers increases dramatically during the rainy season, flooding areas immediately proximal to the margins, and as the water level decreases with the ending of the rainy season, pools of water suitable for mosquito breeding proliferate [169]. 
The massive deforestation observed in the Brazilian Amazon in the 1970s and 1980s brought about significant environmental changes and was associated with increases in malaria transmission, as previously discussed. In addition, large-scale development projects (e.g., road and dam construction) often produce environmental disturbances and social conditions that can be conducive to increases in vector-borne diseases, including malaria [170]. While expanding areas protected under environmental conservation policies would be beneficial to prevent an increase in malaria transmission [171], current trends make it reasonable to expect that deforestation in the Amazon will continue to be a reason for concern [172] driven by varied economic pressures (e.g., cattle ranching, agriculture, mining, and large-scale development projects). To mitigate some of those problems, since 2001 the Brazilian legislation requires that, as part of the licensing of development projects located in malaria endemic areas, an evaluation should be conducted by the Ministry of Health [173].

Considered as the biggest global health threat of the twenty first century [174-176], climate change is likely to have an impact on malaria, despite contrasting results of global models [177-182]. Climatic effects on malaria can occur directly, through extreme events (e.g., drought, flooding), increases in average temperature, and changes in precipitation patterns, but also indirectly, by population displacement, and water and food insecurity, which impact individuals' exposure and vulnerability to infections. Despite the uncertainty embedded in climate change scenarios [183], it is expected that impacts on malaria will be observed, although the impacts and the responses are unlikely to be uniform across and within regions [184]. The magnitude of the impact will depend on: (i) temperature variability [185]; (ii) countries' capacity to anticipate future changes; (iii) adaptation strategies adopted at varied scales; (iv) ongoing malaria control interventions; (v) the possibility that local characteristics that affect malaria risk can be augmented by climatic changes; and (vi) the level of clinical immunity among the population [178]. Since 1996, more than a dozen atypical years (El Niño/La Niña), and at least one extreme drought not at all related to El Niño/La Niña, were observed in the Amazon. Yet, their potential effect on the patterns and level of malaria transmission remains largely unknown.

\section{Deploying effective surveillance}

Surveillance can be defined in different ways [186]. Considering it as an intervention through which data are systematically collected, analysed, and interpreted, so that both symptomatic and asymptomatic cases are identified, triggering quick action to prevent further transmission
[187], then the main challenge is how to properly identify all the cases. Among the potential problems in achieving proper surveillance are human mobility, border issues, asymptomatic infections, and weak health and information systems.

With respect to information systems, Brazil is in a privileged position. Since malaria is one of the diseases that require compulsory notification in the country, a national system gathers information on all malaria tests performed across the country (microscopy and RDT), with demographic information on patients, and with detailed test results. Data are entered locally, and available realtime at the municipal, state and federal levels.

Migratory movements have important malaria implications depending on the levels of immunity among migrants, the underlying patterns of transmission in sending and receiving areas, the local characteristics observed in areas of origin and destination, the individual knowledge about the disease, and the pattern of mobility $[188,189]$. Human mobility is intense in the Brazilian Amazon driven by new economic opportunities (e.g., mining, land availability) or by the need to obtain goods and/or services [190]. In a context of intense human mobility, the challenge of asymptomatic infections is likely to be augmented, since symptomless migrants represent a mobile and silent reservoir of malaria infections. Moreover, human movements can facilitate the reintroduction of malaria in areas that have significantly reduced (or even eliminated) malaria. Critically to that is when unequal control efforts are adopted by neighbouring countries, potentially resulting in a high prevalence of imported cases near the borders [191, 192]. In that regard, one of the critical challenges in the Amazon region is the border between French Guiana, Suriname, and Brazil, where intense mobility (and importation of malaria cases) is fueled by gold mining in French Guiana and Suriname $[116,193]$.

\section{Conclusion}

The Plan for Elimination of Malaria in Brazil, launched in November 2015, is in alignment with the new Sustainable Development Agenda [194], and builds on a unique momentum: the number of malaria cases in the country has reached its lowest levels in 35 years, $P$. falciparum is highly focal, and the geographic boundary of transmission has considerably shrunk. While the prospects for success are good, challenges are many and varied. This paper discussed the challenges ahead, some already present, others a possibility.

In light of the potential challenges, a few issues require some reflection. First, the promotion of collaboration between different government and private sectors (such as, for example, education, agriculture, finance, urban 
planning, transportation, and environment), albeit often difficult to achieve, is of paramount importance to add a development dimension to malaria control [195]. Brazil has already promoted important initiatives in the context of agrarian reform and infrastructure projects in areas suitable to malaria [196], but there is a need and an opportunity for additional collaborations.

Second, as malaria transmission continues to decline, guaranteeing resources for malaria interventions may clash with other pressing and emerging health priorities in the country. In that regard, history makes it very clear that malaria resurgence is a real possibility [197], and it should be avoided. Therefore, sustaining achieved gains, and moving towards further declines is the only option, and multisectoral collaboration can be an important ally in this task.

Third, individual risk perception of malaria and behaviour issues may affect the uptake of interventions and hamper the goals of elimination. Sensitizing individual and communities to maintain or adopt new behaviours that reduce the risk of infections is critically important as areas reach pre-elimination stages. New ways to promote behaviour change campaigns under scenarios of low transmission is an area that needs special attention [198].

Fourth, there is an increasing need for control measures that are tailored for P. vivax, the "last parasite standing". Better strategies for relapse prevention in the presence of G6PD deficiency, and improved point-of-care laboratory diagnosis of low-level P. vivax parasitaemias are required. Helping to fill these knowledge gaps is an important contribution that Brazilian researchers can provide to the current nationwide malaria elimination efforts.

The next 5 years will be critical for elimination goals in the Americas region. Successful outcomes of the malaria elimination plan that Brazil just launched will inspire and provide evidence for similar efforts in other countries. Eventual setbacks in the current trends in malaria transmission in Brazil may suggest the need to fine tune the proposed plan, and may shed light on unforeseen challenges to achieve elimination. How this chapter in the history of malaria control in Brazil will end is highly awaited by the malaria community.

\footnotetext{
Abbreviations

ACT: artemisinin combination therapy; AMI: Amazonian Malaria Initiative; API: annual parasite index; ASMQ: artesunate-mefloquine; CDC: US Centers for Disease Control and Prevention (CDC); CQ: chloroquine; DDT: dichlorodiphenyl-trichloroethane; G6PD: glucose-6-phosphate dehydrogenase; IFAT: indirect fluorescent antibody test; INCRA: National Institute for Land Reform of Brazil; IPTp: intermittent preventive treatment; IRS: indoor residual spraying; ITN: insecticide-treated net; k13: kelch propeller domain; LLIN: long-lasting insecticide-treated bed net; MiP: malaria in pregnancy; NAA: nucleic acid amplification; NMPCP: National Malaria Prevention and Control Programme; PAHO: Pan American Health Organization; PCMAM: Amazon Basin Malaria Control Programme; PCR: polymerase chain reaction; PIACM: Intensification
}

Plan of Malaria Control Activities in the Legal Amazon; POLONOROESTE: Northwest Region Integrated Development Programme; PQ: primaquine; RAVREDA: Amazon Network for the Surveillance of Antimalarial Drug Resistance; RDT: rapid diagnostic test; SNP: single-nucleotide polymorphisms; SP: sulfadoxine-pyrimethamine; USAID: US Agency for International Development; TQ: tafenoquine; WHO: World Health Organization.

\section{Authors' contributions}

MUF and MCC reviewed the literature and wrote the manuscript. Both authors read and approved the final manuscript.

\section{Author details \\ ${ }^{1}$ Department of Parasitology, Institute of Biomedical Sciences, University of São Paulo, Av. Prof. Lineu Prestes 1374, Cidade Universitária, São Paulo, SP 05508-900, Brazil. ${ }^{2}$ Department of Global Health and Population, Harvard T.H. Chan School of Public Health, 665 Huntington Avenue, Building I, Room 1113, Boston, MA 02115, USA.}

\section{Acknowledgements}

Recent field studies reviewed here have been funded by grants from the research grants from the National Institute of Allergy and Infectious Diseases (NIAID), National Institutes of Health (NIH), (U19 AI089681 to Joseph M. Vinetz) and the Fundação de Amparo à Pesquisa do Estado de São Paulo (FAPESP, 2009/52729-9 to MUF), Brazil. MCC (2013/17259-7) was supported by FAPESP. MUF receives a senior researcher scholarship from the Conselho Nacional de Desenvolvimento Científico e Tecnológico (CNPq) of Brazil.

\section{Competing interests}

The authors declare that they have no competing interests.

Received: 4 March 2016 Accepted: 10 May 2016

Published online: 20 May 2016

References

1. Pan American Health Organization. Interactive malaria statistics. Washington, DC: PAHO; 2016. http://www.paho.org/hq/index. php?option $=$ com_content\&task=view\&id $=2632 \&$ ltemid $=2130$. Accessed 1 Feb 2016.

2. Tatem AJ, Smith DL, Gething PW, Kabaria CW, Snow RW, Hay SI. Ranking of elimination feasibility between malaria-endemic countries. Lancet. 2010;376:1579-91.

3. Deane LM. Malaria studies and control in Brazil. Am J Trop Med Hyg. 1988;38:223-30.

4. Chagas C. Luta Contra a Malária. Rio de Janeiro; 1934. p. 24.

5. Cruz O. Prophylaxis of malaria in central and southern Brazil. In: Ross R, editor. The prevention of malaria. New York: E.P. Dutton \& Company; 1910. p. 390-9.

6. Silveira AC, Rezende DF. Avaliação da estratégia global de controle integrado da malária no Brasil. Brasília: Organização Pan-Americana da Saúde; 2001. p. 120.

7. Deane LM. A história da evolução dos conhecimentos sobre a malária. Rio de Janeiro; 1986. p. 51.

8. Hochman G, Mello MTB, Santos PRE. A malária em foto: imagens de campanhas e ações no Brasil da primeira metade do século XX. Hist Ciênc Saúde. 2002;9:233-73.

9. Neiva A. Profilaxia da malaria e trabalhos de engenharia: notas, comentários, recordações. Revista do Clube de Engenharia, vol. VI. 1940. p. 60-75.

10. Parmakelis A, Russello MA, Caccone A, Marcondes CB, Costa J, Forattini $\mathrm{OP}$, et al. Historical analysis of a near disaster: Anopheles gambiae in Brazil. Am J Trop Med Hyg. 2008;78:176-8.

11. Deane LM. A história do Anopheles gambiae no Brasil. In: III Seminário de Vetores Urbanos e Animais Sinatrópicos-4 $4^{a}$ Reunião Brasileira sobre Simulídeos. III Seminário de Vetores Urbanos e Animais Sinatrópicos4a. Reunião Brasileira sobre Simulídeos. Rio de Janeiro; 1990.

12. Soper FL, Wilson DB. Anopheles gambiae in Brazil, 1930 to 1940. New York City: Rockefeller Foundation; 1943. 
13. Farid MA. The malaria programme-from euphoria to anarchy. World Health Forum. 1980;1:8-33.

14. Norman TJ, Baley MA. The biomathematics of malaria. London: Oxford University Press; 1982.

15. Litsios S. The tomorrow of malaria. Wellington: Pacific Press; 1997. p. 186.

16. Pina-Costa A, Brasil P, Santi SMD, de Araujo MP, Suárez-Mutis MC, Santelli ACFS, et al. Malaria in Brazil: what happens outside the Amazonian endemic region. Mem Inst Oswaldo Cruz. 2014;109:618-33.

17. Silva R, Paiva CHA. The Juscelino Kubitschek government and the Brazilian Malaria Control and Eradication Working Group: collaboration and conflicts in Brazilian and international health agenda, 1958-1961. Hist Ciênc Saúde Manguinhos. 2015;22:95-114.

18. Tauil P, Deane L, Sabroza P, Ribeiro C. A malária no Brasil. Cad Saude Publ. 1985;1:71-111.

19. Nájera JA, González-Silva M, Alonso PL. Some lessons for the future from the Global Malaria Eradication Programme (1955-1969). PLoS Med. 2011;8:e1000412.

20. Silva R, Hochman G. Um método chamado Pinotti: sal medicamentoso, malária e saúde internacional (1952-1960). Hist Ciênc, Saúde Manguinhos. 2011;18:519-44.

21. Pinotti M, Lôbo AGS, Damasceno G, Soares R. Experiências de campo com o sal cloroquinado. Revista Brasileira de Malariologia e Doenças Tropicais. 1955;7:5-23.

22. Clyde DF. Suppression of malaria in Tanzania with the use of medicated salt. Bull World Health Organ. 1966;35:962-8.

23. Giglioli G, Rutten FJ, Ramjattan S. Interruption of malaria transmission by chloroquinized salt in Guyana, with observations on a chloroquineresistant strain of Plasmodium falciparum. Bull World Health Organ. 1967;36:283-301.

24. Coimbra MELS. Política pública e saúde: o caso da malária no Brasil. Análise e Conjuntura. 1987;2:72-90.

25. Val FF, Sampaio VS, Cassera MB, Andrade RT, Tauil PL, Monteiro WM, et al. Plasmodium vivax malaria elimination: should innovative ideas from the past be revisited? Mem Inst Oswaldo Cruz. 2014;109:522-4

26. Sawyer DR. Frontier malaria in the Amazon region of Brazil: types of malaria situations and some implications for control. Brasília: PAHO/ WHO/TDR; 1988.

27. Mahar DJ. Frontier development policy in Brazil: a study of Amazonia. New York: Praeger; 1979.

28. Silva GC. Geopolítica do Brasil. Rio de Janeiro: José Olympio; 1967.

29. Marques AC. Human migration and the spread of malaria in Brazil. Parasitol Today. 1987;3:166-70.

30. Sant'Ana MMM. Uma avaliação das políticas recentes de desenvolvimento regional no Brasil: Programa de Desenvolvimento da Região Noroeste_POLONOROESTE. Revista Econômica do Nordeste. 1994;25:499-528

31. Martine G. Rondônia and the fate of small producers. In: Goodman D, Hall AL, editors. The future of Amazonia: destruction or sustainable development?. Basingstoke: Macmillan Press; 1990. p. 23-48.

32. Perdigão F, Bassegio L. Migrantes Amazônicos-Rondônia: a trajetória da ilusão. São Paulo: Edições Loyola; 1992.

33. World Bank. World Bank approaches to the environment in Brazil: a review of selected projects. In: The POLONOROESTE program, vol. 5. Washington: The World Bank; 1992. p. 344.

34. Fearnside PM. Deforestation in Brazilian Amazonia: history, rates, and consequences. Conservat Biol. 2005;19:680-8.

35. Castro MC, Monte-Mór RL, Sawyer DO, Singer BH. Malaria risk on the Amazon frontier. Proc Natl Acad Sci USA. 2006;103:2452-7.

36. Sawyer DR, Sawyer DO. The malaria transition and the role of social science research. In: Chen LC, editor. Advancing the health in developing countries: the role of social research. Westport: Auburn House; 1992. p. 105-22.

37. Sinka ME, Rubio-Palis Y, Manguin S, Patil AP, Temperley WH, Gething PW, et al. The dominant Anopheles vectors of human malaria in the Americas: occurrence data, distribution maps and bionomic précis. Parasit Vectors. 2010;3:72.

38. Hahn MB, Gangnon RE, Barcellos C, Asner GP, Patz JA. Influence of deforestation, logging, and fire on malaria in the Brazilian Amazon. PLoS One. 2014;9:e85725.

39. Vittor AY, Gilman RH, Tielsch J, Glass G, Shields T, Lozano WS, et al. The effect of deforestation on the human-biting rate of Anopheles darlingi, the primary vector of falciparum malaria in the Peruvian Amazon. Am J Trop Med Hyg. 2006;74:3-11.

40. Vittor AY, Pan W, Gilman RH, Tielsch J, Glass G, Shields T, et al. Linking deforestation to malaria in the Amazon: characterization of the breeding habitat of the principal malaria vector, Anopheles darlingi. Am J Trop Med Hyg. 2009;81:5-12.

41. Barbieri AF, Sawyer DO, Soares-Filho B. Population and land use effects on malaria prevalence in the Southern Brazilian Amazon. Human Ecol. 2005;33:847-74.

42. Sawyer D. Economic and social consequences of malaria in new colonization projects in Brazil. Soc Sci Med. 1993;37:1131-6.

43. Silva LCE. O que mostram os indicadores sobre a pobreza na década perdida. Brasília: Instituto de Pesquisa Econômica Aplicada_-IPEA. Textos para Discussão. 1992. p. 274.

44. Cavasini MTV, Ribeiro WL, Kawamoto F, Ferreira MU. How prevalent is Plasmodium malariae in Rondônia, Western Brazilian Amazon? Rev Soc Bras Med Trop. 2000;33:489-92.

45. Scopel KKG, Fontes CJ, Nunes AC, Horta MF, Braga EM. High prevalence of Plasmodium malariae infections in a Brazilian Amazon endemic area (Apiacás-Mato Grosso State) as detected by polymerase chain reaction. Acta Trop. 2005;90:61-4.

46. Cheng Q, Cunningham J, Gatton ML. Systematic review of sub-microscopic P. vivax infections: prevalence and determining factors. PLoS Negl Trop Dis. 2015;9:e3413.

47. White NJ, Imwong M. Relapse. Adv Parasitol. 2012;80:113-50.

48. Luzzatto L, Seneca E. G6PD deficiency: a classic example of pharmacogenetics with on-going clinical implications. Br J Haematol. 2014;164:469-80.

49. Douglas NM, Simpson JA, Phyo AP, Siswantoro H, Hasugian AR, Kenangalem E, et al. Gametocyte dynamics and the role of drugs in reducing the transmission potential of Plasmodium vivax. J Infect Dis. 2013;208:801-12.

50. Lima NF, Bastos MS, Ferreira MU. Plasmodium vivax: reverse transcriptase real-time PCR for gametocyte detection and quantitation in clinical samples. Exp Parasitol. 2012;132:348-54.

51. Akhavan D, Musgrove P, Abrantes A, Gusmão RA. Cost-effective malaria control in Brazil: cost-effectiveness of a malaria control program in the Amazon Basin of Brazil, 1988-1996. Soc Sci Med. 1999;49:1385-99.

52. Loiola CCP, Silva CJM, Tauil PL. Controle da malária no Brasil: 1965 a 2001. Pan Am J Public Health. 2002;11:235-44.

53. Guimarães RM, Asmus Cl, Meyer A. DDT reintroduction for malaria control: the cost-benefit debate for public health. Cad Saude Publ. 2007;23:2835-44.

54. Ministério da Saúde, Secretaria de Vigilância em Saúde. Plano de Intensificação das Ações de Controle da Malária na Amazônia LegalRelatório Executivo. Brasília: Ministério da Saúde, Secretaria de Vigilância em Saúde; 2000.

55. Ministério da Saúde, Secretaria de Vigilância em Saúde. Programa Nacional de Prevenção e Controle da Malária—PNCM. Brasília: Ministério da Saúde, Secretaria de Vigilância em Saúde; 2003. p. 132.

56. Ferreira MU, da Silva-Nunes M. Evidence-based public health and prospects for malaria control in Brazil. J Infect Dev Ctries. 2010;4:533-45.

57. WHO. Health in 2015: from MDGs, millennium development goals to SDGs, sustainable development goals. Geneva: World Health Organization; 2015. p. 216

58. Ministério da Saúde. Ministério da Saúde lança Plano de Eliminação da malária no Brasil. 2015. http://portalsaude.saude.gov.br/index. php/cidadao/principal/agencia-saude/20609-ministerio-da-saudelanca-plano-de-eliminacao-da-malaria-no-brasil. Accessed 1 Feb 2016.

59. Ministério da Saúde. Brasil tem o menor número de casos de malária dos últimos 35 anos. 2016. http://www.brasil.gov.br/saude/2016/04/ brasil-tem-o-menor-numero-de-casos-de-malaria-dos-ultimos-35-anos. Accessed 1 Apr 2016

60. Avery-Jones S, Ferreira-Neto JA. Symptomless Plasmodium vivax parasitaemias and malaria eradication in Santa Catarina State, Brazil (WHO/ MAL/64.469). Geneva: World Health Organization; 1964.

61. Marrelli MT, Malafronte RS, Sallum MA, Natal D. Kerteszia subgenus of Anopheles associated with the Brazilian Atlantic rainforest: current knowledge and future challenges. Malar J. 2007;6:127. 
62. Carvalho ME, Glasser CM, Santos LA, Ciaravolo RMC. Nota sobre o encontro de casos autóctones de malária vivax por meio de técnica sorológica, em São Paulo. Cad Saude Publ. 1985;1:250-2.

63. Carvalho ME, Glasser CM, Ciaravolo RMC, Etzel A, Santos LA, Ferreira CS. Sorologia de malária vivax no foco Aldeia dos Índios, município de Peruíbe, Estado de São Paulo, 1984 a 1986. Cad Saude Publ. 1988;4:276-92.

64. Alves FP, Durlacher RR, Menezes MJ, Krieger H, Silva LHP, Camargo EP. High prevalence of asymptomatic Plasmodium vivax and Plasmodium falciparum infections in native Amazonian populations. Am J Trop Med Hyg. 2002;66:641-8.

65. Ladeia-Andrade S, Ferreira MU, Carvalho ME, Curado I, Coura JR. Age-dependent acquisition of protective immunity to malaria in riverine populations of the Amazon Basin of Brazil. Am J Trop Med Hyg. 2009:80:452-9.

66. Coura JR, Suarez-Mutis M, Ladeia-Andrade S. A new challenge for malaria control in Brazil: asymptomatic Plasmodium infection-a review. Mem Inst Oswaldo Cruz. 2006;101:229-37.

67. Prata A, Urdaneta M, McGreevy PB, Tada MS. Infrequency of asymptomatic malaria in an endemic area in Amazonas, Brazil. Rev Soc Bras Med Trop. 1988;21:51-4.

68. Camargo LM, Ferreira MU, Krieger $H$, de Camargo EP, da Silva LP. Unstable hypoendemic malaria in Rondônia (western Amazon region, Brazil): epidemic outbreaks and work-associated incidence in an agroindustrial rural settlement. Am J Trop Med Hyg. 1994;51:16-25.

69. Camargo LM, dal Colletto GM, Ferreira MU, Gurgel SM, Escobar AL, Marques A, et al. Hypoendemic malaria in Rondônia (Brazil, western Amazon region): seasonal variation and risk groups in an urban locality. Am J Trop Med Hyg. 1996;55:32-8.

70. Duarte EC, Gyorkos TW, Pang L, Abrahamowicz M. Epidemiology of malaria in a hypoendemic Brazilian Amazon migrant population: a cohort study. Am J Trop Med Hyg. 2004;70:229-37.

71. da Silva-Nunes M, Codeco CT, Malafronte RS, da Silva NS, Juncansen C, Muniz PT, et al. Malaria on the Amazonian frontier: transmission dynamics, risk factors, spatial distribution, and prospects for control. Am J Trop Med Hyg. 2008;79:624-35.

72. da Silva NS, da Silva-Nunes M, Malafronte RS, Menezes MJ, D'Arcadia RR, Komatsu NT, et al. Epidemiology and control of frontier malaria in Brazil: lessons from community-based studies in rural Amazonia. Trans R Soc Trop Med Hyg. 2010;104:343-50.

73. Barbosa S, Gozze AB, Lima NF, Batista CL, Bastos MS, Nicolete VC, et al. Epidemiology of disappearing Plasmodium vivax malaria: a case study in rural Amazonia. PLoS Negl Trop Dis. 2014;8:e3109.

74. da Silva-Nunes M, Ferreira MU. Clinical spectrum of uncomplicated malaria in semi-immune Amazonians: beyond the "symptomatic" vs "asymptomatic" dichotomy. Mem Inst Oswaldo Cruz. 2007;102:341-7.

75. Alves FP, Gil LHS, Marrelli MT, Ribolla PEM, Camargo EP, Silva LHP. Asymptomatic carriers of Plasmodium spp. as infection source for malaria vector mosquitoes in the Brazilian Amazon. J Med Entomol. 2005:42:777-9.

76. Sturrock HJW, Hsiang MS, Cohen JM, Smith DL, Greenhouse B, Bousema T, Gosling RD. Targeting asymptomatic malaria infections: active surveillance in control and elimination. PLoS Med. 2013;10:e1001467.

77. Perkins M, Bell D. Working without a blindfold: the critical role of diagnostics in malaria control. Malar J. 2008;7:S5.

78. Baniecki ML, Faust AL, Schaffner SF, Park DJ, Galinsky K, Daniels RF, et al. Development of a single nucleotide polymorphism barcode to genotype Plasmodium vivax infections. PLoS Negl Trop Dis. 2015;9:e0003539.

79. Karunaweera ND, Ferreira MU, Hartl DL, Wirth DF. Fourteen polymorphic microsatellite DNA markers for the human malaria parasite Plasmodium vivax. Mol Ecol Notes. 2007;7:172-5.

80. Lutz A. Waldmosquitos und Waldmalaria. Centralblatt für Bakteriologie, Parasitenkunde und Infektionskrankheiten. 1903;33:282-92.

81. Downs WG, Pittendrigh CS. Bromeliad malaria in Trinidad, British West Indies. Am J Trop Med Hyg. 1946;26:47-66.

82. Gadelha P. From, "forest malaria" to "bromeliad malaria": a case study of scientific controversy and malaria control. Parassitologia. 1994;36:175-95.

83. Rachou RG. Campaign against anophelines of the sub-genus Kerteszia in the south of Brazil. Rev Bras Malariol Doencas Trop. 1952;4:245-54 (in Portuguese)
84. Deane LM. Simian malaria in Brazil. Mem Inst Oswaldo Cruz. 1992;87:1-20.

85. Laporta G, Burattini M, Levy D, Fukuya L, de Oliveira T, Maselli L, et al. Plasmodium falciparum in the southeastern Atlantic forest: a challenge to the bromeliad-malaria paradigm? Malar J. 2015;14:181.

86. São Thiago PT. História da malária em Santa Catarina. Master's thesis. Federal University of Santa Catarina, 2003.

87. Griffing SM, Tauil PL, Udhayakumar V, Silva-Flannery L. A historical perspective on malaria control in Brazil. Mem Inst Oswaldo Cruz. 2015;110:701-18.

88. Okell LC, Bousema T, Griffin JT, Ouédraogo AL, Ghani AC, et al. Factors determining the occurrence of submicroscopic malaria infections and their relevance for control. Nat Commun. 2012;3:1237.

89. WHO. Evidence review group on malaria diagnosis in low transmission setting. Meeting Report. Geneva: World Health Organization; 2014. p. 33.

90. Bomtempo JM. Memória sobre algumas enfermidades do Rio de Janeiro, e mui particularmente sobre o abuso geral, e pernicioso efeito da aplicação da preciosa casca Peruviana, ou quina. Rio de Janeiro: Typographia Nacional; 1825.

91. Neiva A. Formação de raça do hematozoario do impaludismo resistente a quinina. Mem Inst Oswaldo Cruz. 1910;2:131-40.

92. Couto M. Les injections endo-veineuses du bleu de méthylène dans le paludisme. Bull Soc Pathol Exot. 1908;1:292-5.

93. Benchimol JL, Silva AFC. Railroads, disease, and tropical medicine in Brazil under the First Republic. Hist Ciênc Saúde Manguinhos. 2008:15:719-62.

94. da Silva AFC, Benchimol JL. Malaria and quinine resistance: a medical and scientific issue between Brazil and Germany (1907-19). Med History. 2014;58:1-26.

95. Kremsner PG, Zotter GM, Feldmeier H, Graninger W, Kollaritsch M, Wiedermann $\mathrm{G}$, et al. In vitro drug sensitivity of Plasmodium falciparum in Acre, Brazil. Bull World Health Organ. 1989;67:289-93.

96. Zalis MG, Pang L, Silveira MS, Milhous WK, Wirth DF. Characterization of Plasmodium falciparum isolated from the Amazon region of Brazil: evidence for quinine resistance. Am J Trop Med Hyg. 1998;58:630-7.

97. de Alencar FEC, Cerutti C, Durlacher RR, Boulos M, Alves FP, Milhous W, et al. Atovaquone and proguanil for the treatment of malaria in Brazil. J Infect Dis. 1997;175:1544-7.

98. Duarte EC, Fontes CJF, Gyorkos TW, Abrahamowicz M. Randomized controlled trial of artesunate plus tetracycline versus standard treatment (quinine plus tetracycline) for uncomplicated Plasmodium falciparum malaria in Brazil. Am J Trop Med Hyg. 1996;54:197-202.

99. de Souza JM. Epidemiological distribution of Plasmodium falciparum drug resistance in Brazil and its relevance to the treatment and control of malaria. Mem Inst Oswaldo Cruz. 1992;87:343-8.

100. Rodrigues DC. Casos de malária por Plasmodium falciparum resistentes ao tratamento pela cloroquina. Arquivos de Higiene e Saúde Pública. 1961;26:231-5

101. Silva JR. Resistência do P. falciparum à ação da cloroquina. O Hospital. 1961;60:43-58.

102. Moore DV, Lanier JE. Observations on two Plasmodium falciparum infections with an abnormal response to chloroquine. Am J Trop Med Hyg. 1961;10:5-9.

103. Wootton JC, Feng X, Ferdig MT, Cooper RA, Mu J, Baruch DI, et al. Genetic diversity and chloroquine selective sweeps in Plasmodium falciparum. Nature. 2002:418:320-3.

104. Cortese JF, Caraballo A, Contreras CE, Plowe CV. Origin and dissemination of Plasmodium falciparum drug-resistance mutations in South America. J Infect Dis. 2002;186:999-1006.

105. Walker AJ, Lopez-Antunano FJ. Response to drugs of South American strains of Plasmodium falciparum. Trans R Soc Trop Med Hyg. 1968;62:654-67.

106. Almeida-Netto JC, Oliveira GSC, Sampaio JAA. Resistência do Plasmodium falciparum à associação sulfamidicos-antifólicos na Região Centro-Oeste do Brasil. Dados referentes ao estudo de 104 casos. Rev Patol Trop. 1972;1:385-93.

107. Suárez-Mutis MC, de Souza PP, Freitas LF, Miranda ES, Campos MR, Osorio-de-Castro CGS. Pharmaceutical services for endemic situations in the Brazilian Amazon: organization of services and prescribing practices 
for Plasmodium vivax and Plasmodium falciparum non-complicated malaria in high-risk municipalities. Malar J. 2011;10:335.

108. Noronha E, Alecrim MG, Romero GAS, Macêdo V. RIII mefloquine resistance in children with falciparum malaria in Manaus, AM, Brazil. Rev Soc Bras Med Trop. 2000;33:201-5.

109. Alencar FH, Ferraroni JJ, Shrimpton R. Resistência do Plasmodium falciparum ao Fansidar, quinina e tetraciclina. Rev Saude Publ. 1982;16:299-302.

110. Cerutti C, Durlacher RR, de Alencar FEC, Segurado AAC, Pang LW. In vivo efficacy of mefloquine for the treatment of falciparum malaria in Brazil. J Infect Dis. 1999;180:2077-80.

111. Souza JM. Mefloquine clinical trials—-therapeutical experience with mefloquine alone and combination (MSP) in brazilian male subjects with falciparum malaria. Mem Inst Oswaldo Cruz. 1986;81:259-68.

112. Santelli A, Ribeiro I, Daher A, Boulos M, Marchesini P, dos Santos RL, et al. Effect of artesunate-mefloquine fixed-dose combination in malaria transmission in Amazon Basin communities. Malar J. 2012;11:286.

113. Ladeia-Andrade S, de Melo GN, de Souza-Lima RC, Salla LC, Bastos MS, Rodrigues PT, Luz FD, Ferreira MU. No clinical or molecular evidence of Plasmodium falciparum resistance to artesunate-mefloquine in northwestern Brazil. Am J Trop Med Hyg. 2016. doi:10.4269/ajtmh.16-0017.

114. Adhin MR, Labadie-Bracho M, Vreden S. Gold mining areas in Suriname: reservoirs of malaria resistance? Infect Drug Resist. 2014;7:111-6.

115. Vreden SGS, Jitan JK, Bansie RD, Adhin MR. Evidence of an increased incidence of day 3 parasitaemia in Suriname: an indicator of the emerging resistance of Plasmodium falciparum to artemether. Mem Inst Oswaldo Cruz. 2013;108:968-73.

116. Nacher M, Guérin P, Demar-Pierre M, Djossou F, Nosten F, Carme B. Made in Europe: will artemisinin resistance emerge in French Guiana? Malar J. 2013;12:152.

117. Chenet SM, Akinyi Okoth S, Huber CS, Chandrabose J, Lucchi NW, Talundzic $E$, et al. Independent emergence of the Plasmodium falciparum kelch propeller domain mutant allele C580Y in Guyana. J Infect Dis. 2016;213:1472-5.

118. Price RN, von Seidlein L, Valecha N, Nosten F, Baird JK, White NJ. Global extent of chloroquine-resistant Plasmodium vivax: a systematic review and meta-analysis. Lancet Infect Dis. 2014;14:982-91.

119. Duarte EC, Pang LW, Ribeiro LC, Fontes CJ. Association of subtherapeutic dosages of a standard drug regimen with failures in preventing relapses of vivax malaria. Am J Trop Med Hyg. 2001;65:471-6.

120. Brasil. Guia prático de tratamento da malária no Brasil. Brasília: Ministério da Saúde, Secretaria de Vigilância em Saúde. Departamento de Vigilância Epidemiológica; 2010. p. 36.

121. Gonçalves LA, Cravo P, Ferreira MU. Emerging Plasmodium vivax resistance to chloroquine in South America: an overview. Mem Inst Oswaldo Cruz. 2014;109:534-9.

122. Phillips EJ, Keystone JS, Kain KC. Failure of combined chloroquine and high-dose primaquine therapy for Plasmodium vivax malaria acquired in Guyana, South America. Clin Infect Dis. 1996;23:1171-3.

123. Ruebush TK, Zegarra J, Cairo J, Andersen EM, Green M, Pillai DR, et al. Chloroquine-resistant Plasmodium vivax malaria in Peru. Am JTrop Med Hyg. 2003;69:548-52.

124. de Santana Filho FS, de Lima Arcanjo AR, Chehuan YM, Costa MR, Martinez-Espinosa FE, et al. Chloroquine-resistant Plasmodium vivax, Brazilian Amazon. Emerg Infect Dis. 2007;13:1125-6.

125. Marques MM, Costa MRF, Santana Filho FS, Vieira JLF, Nascimento MTS, Brasil LW, et al. Plasmodium vivax chloroquine resistance and anemia in the Western Brazilian Amazon. Antimicrob Agents Chemother. 2013:58:342-7.

126. Douglas NM, Anstey NM, Angus BJ, Nosten F, Price RN. Artemisinin combination therapy for vivax malaria. Lancet Infect Dis. 2010;10:405-16.

127. Egan TJ. Chloroquine and primaquine: combining old drugs as a new weapon against falciparum malaria? Trends Parasitol. 2006;22:235-7.

128. Naing C, Aung K, Win DK, Wah MJ. Efficacy and safety of chloroquine for treatment in patients with uncomplicated Plasmodium vivax infections in endemic countries. Trans R Soc Trop Med Hyg. 2010;104:695-705.

129. Baird K. Origins and implications of neglect of G6PD deficiency and primaquine toxicity in Plasmodium vivax malaria. Pathog Glob Health. 2015;109:93-106.
130. Monteiro WM, Val FFA, Siqueira AM, Franca GP, Sampaio VS, Melo GC, et al. G6PD deficiency in Latin America: systematic review on prevalence and variants. Mem Inst Oswaldo Cruz. 2014;109:553-68.

131. Nkhoma ET, Poole C, Vannappagari V, Hall SA, Beutler E. The global prevalence of glucose-6-phosphate dehydrogenase deficiency: a systematic review and meta-analysis. Blood Cells Mol Dis. 2009:42:267-78.

132. Monteiro W, Franca G, Melo G, Queiroz A, Brito M, Peixoto H, et al. Clinical complications of G6PD deficiency in Latin American and Caribbean populations: systematic review and implications for malaria elimination programmes. Malar J. 2014;13:70.

133. Boulos M, Amato Neto V, Dutra AP, Di Santi SM, Shiroma M. Frequency of malaria relapse due to Plasmodium vivax in a non-endemic region (Sao Paulo, Brazil). Rev Inst Med Trop Sao Paulo. 1991;33:143-6 (in Portuguese).

134. Reddy P, Flaherty JP. Plasmodium vivax malaria relapses after primaquine prophylaxis. Emerg Infect Dis. 2006;12:1795-6.

135. Nayar JK, Baker RH, Knight JW, Sullivan JS, Morris CL, Richardson BB, et al. Studies on a primaquine-tolerant strain of Plasmodium vivax from Brazil in Aotus and Saimiri monkeys. J Parasitol. 1997:83:739-45.

136. Hill DR, Baird JK, Parise ME, Lewis LS, Ryan ET, Magill AJ. Primaquine: report from CDC expert meeting on malaria chemoprophylaxis I. Am J Trop Med Hyg. 2006;75:402-15.

137. WHO. Guidelines for the treatment of malaria. 3rd ed. Geneva: World Health Organization; 2015. p. 316.

138. Llanos-Cuentas A, Lacerda MV, Rueangweerayut R, Krudsood S, Gupta SK, Kochar SK, et al. Tafenoquine plus chloroquine for the treatment and relapse prevention of Plasmodium vivax malaria (DETECTIVE): a multicentre, double-blind, randomised, phase $2 \mathrm{~b}$ dose-selection study. Lancet. 2014;383:1049-58.

139. Desai M, ter Kuile FO, Nosten F, McGready R, Asamoa Kwame, Brabin PB, et al. Epidemiology and burden of malaria in pregnancy. Lancet Infect Dis. 2007;7:93-104.

140. Macgregor JD, Avery JG. Malaria transmission and fetal growth. BMJ. 1974;3:433-6.

141. Marchesini P, Costa FTM, Marinho CRF. A decade of malaria during pregnancy in Brazil: what has been done concerning prevention and management. Mem Inst Oswaldo Cruz. 2014;109:706-8.

142. Mayor A, Moro L, Aguilar R, Bardají A, Cisteró P, Serra-Casas E, et al. How hidden can malaria be in pregnant women? Diagnosis by microscopy, placental histology, polymerase chain reaction and detection of histidine-rich protein 2 in plasma. Clin Infect Dis. 2012;54:1561-8.

143. Nosten F, McGready R, Simpson JA, Thwai KL, Balkan S, Cho T, et al. Effects of Plasmodium vivax malaria in pregnancy. Lancet. 1999;354:546-9.

144. McGready R, Davison BB, Stepniewska K, Cho T, Shee H, Brockman A, et al. The effects of Plasmodium falciparum and $P$. vivax infections on placental histopathology in an area of low malaria transmission. Am J Trop Med Hyg. 2004;70:398-407.

145. Souza RM, Ataíde R, Dombrowski JG, Ippólito V, Aitken EH, Valle SN, et al. Placental histopathological changes associated with Plasmodium vivax infection during pregnancy. PLoS Negl Trop Dis. 2013;7:e2071.

146. Machado Filho AC, da Costa EP, da Costa EP, Reis IS, Fernandes EAC, Paim BV, et al. Effects of vivax malaria acquired before 20 weeks of pregnancy on subsequent changes in fetal growth. Am J Trop Med Hyg. 2014;90:371-6

147. Martínez-Espinosa FE, Daniel-Ribeiro CT, Alecrim WD. Malaria during pregnancy in a reference centre from the Brazilian Amazon: unexpected increase in the frequency of Plasmodium falciparum infections. Mem Inst Oswaldo Cruz. 2004:99:19-21.

148. Parekh FK, Hernandez JN, Krogstad DJ, Casapia WM, Branch OH. Prevalence and risk of Plasmodium falciparum and P. vivax malaria among pregnant women living in the hypoendemic communities of the Peruvian Amazon. Am J Trop Med Hyg. 2007;77:451-7.

149. WHO. Policy brief for the implementation of intermittent preventive treatment of malaria in pregnancy using sulfadoxine-pyrimethamine (IPTp-SP). Geneva: World Health Organization; 2013.

150. Maheu-Giroux M, Castro MC. Factors affecting providers' delivery of intermittent preventive treatment for malaria in pregnancy: a fivecountry analysis of national service provision assessment surveys. Malar J. 2014;13:440. 
151. WHO. Evidence review group: intermittent preventive treatment of malaria in pregnancy (IPTp) with sulfadoxine-pyrimethamine (SP). Meeting report. Geneva: World Health Organization; 2012.

152. Serviço Especial de Saúde Pública. Adultos de anophelinos examinados pelo Laboratório Central e Divisão de Malária. Julho de 1942—Junho de 1946. SESP__Programa da Amazônia. Casa de Oswaldo Cruz (FIOCRUZ) collection. LD/TP/19420740; 1946.

153. Deane LM. A chronological summary of the knowledge on the anophelines and their relation to malaria in the Amazon region of Brazil. Brasília: PAHO/WHO/TDR; 1988.

154. Elliott R. The influence of vector behavior on malaria transmission. Am J Trop Med Hyg. 1972;21:755-63.

155. Deane LM. Malaria vectors in Brazil. Mem Inst Oswaldo Cruz. 1986;81:5-14

156. Rosa-Freitas MG, Broomfield G, Priestman A, Milligan PJM, Momen H, Molyneux DH. Cuticular hydrocarbons, isoenzymes and behavior of three populations of Anopheles darlingi from Brazil. J Am Mosquito Control Assoc. 1992:8:357-66.

157. Klein TA, Lima JBP. Seasonal distribution and biting patterns of Anopheles mosquitoes in Costa Marques, Rondônia, Brazil. J Am Mosquito Control Assoc. 1990;6:700-7.

158. Tadei WP. Considerações sobre as espécies de anopheles e a transmissão da malária na Amazônia. Manaus: INPA—Instituto Nacional de Pesquisas da Amazônia; 1991. p. 16.

159. Conn JE, Ribolla PE. Ecology of Anopheles darlingi, the primary malaria vector in the americas and current nongenetic methods of vector control. In: Adelman ZN, editor. Genetic Control of Malaria and Dengue. Oxford: Academic Press; 2015. p. 81-102.

160. Lengeler $C$. Insecticide-treated bed nets and curtains for preventing malaria. Cochrane Database Syst Rev. 2004;2:CD000363.

161. Alexander N, Rodríguez M, Pérez L, Caicedo JC, Cruz J, Prieto G, et al. Case-control study of mosquito nets against malaria in the Amazon Region of Colombia. Am J Trop Med Hyg. 2005;73:140-8.

162. Magris M, Rubio-Palis Y, Alexander N, Ruiz B, Galvan N, Frias D, et al. Community-randomized trial of lambdacyhalothrin-treated hammock nets for malaria control in Yanomami communities in the Amazon region of Venezuela. Trop Med Int Health. 2007;12:392-403.

163. Martins L. Uso de mosquiteiro especial reduz em $32 \%$ casos de malária no Acre. In: Agencia Brasil. 2008. http://memoria.ebc.com.br/agenciabrasil/noticia/2008-02-18/uso-de-mosquiteiro-especial-reduz-em32-casos-de-malaria-no-acre. Accessed 1 Dec 2015.

164. Brasil. Ministério da Saúde: Guia para Gestão Local do Controle da Malária. Módulo 2-Controle Vetorial. In: Série B Normas e Manuais Técnicos. Brasília, DF: Ministério da Saúde. Secretaria de Vigilância em Saúde. Diretoria Técnica de Gestão; 2009. p. 59.

165. Ferreira FAS, Arcos AN, Sampaio RTM, Rodrigues IB, Tadei WP. Effect of Bacillus sphaericus Neide on Anopheles (Diptera: Culicidae) and associated insect fauna in fish ponds in the Amazon. Rev Bras Entomol. 2015;59:234-9.

166. WHO. World Malaria Report 2015. Geneva: World Health Organization; 2015. p. 243.

167. United Nations. OMS, Brasil e parceiro lançam plano de eliminação da malária no país. 2015. https://nacoesunidas.org/oms-brasil-e-parceirolancam-plano-de-eliminacao-da-malaria-no-pais/. Accessed 1 Nov 2015.

168. WHO. Strategy for malaria elimination in the greater Mekong subregion (2015-2030). Geneva: World Health Organization; 2015. p. 65.

169. Peixoto A. O problema sanitário da Amazônia. Rio de Janeiro; 1917. p. 28.

170. Lerer LB, Scudder T. Health impacts of large dams. Environ Impact Assess Rev. 1999;19:113-23.

171. Bauch SC, Birkenbach AM, Pattanayak SK, Sills EO. Public health impacts of ecosystem change in the Brazilian Amazon. Proc Natl Acad Sci USA. 2015;112:7414-9.

172. Fearnside PM. Environment: deforestation soars in the Amazon. Nature. 2015:521:423.

173. Brasil: Resolução CONAMA n. ${ }^{\circ} 286$, de 30 de Agosto de 2001. Dispõe sobre o licenciamento ambiental de empreendimentos nas regiões endêmicas de malária. 2001.

174. Costello A, Abbas M, Allen A, Ball S, Bell S, Bellamy R, et al. Managing the health effects of climate change. Lancet. 2009;373:1693-733.
175. Watts N, Adger WN, Agnolucci P, Blackstock J, Byass P, Cai W, Chaytor $S$, et al. Health and climate change: policy responses to protect public health. Lancet. 2015;386:1861-914.

176. WHO. Protecting health from climate change: global research priorities. Geneva: World Health Organization; 2009.

177. Gething PW, Smith DL, Patil AP, Tatem AJ, Snow RW, Hay SI. Climate change and the global malaria recession. Nature. 2010;465:342-6.

178. Laneri K, Paul RE, Tall A, Faye J, Diene-Sarr F, Sokhna C, et al. Dynamical malaria models reveal how immunity buffers effect of climate variability. Proc Natl Acad Sci USA. 2015;112:8786-91.

179. Martens P, Kovats RS, Nijhof S, Vries Pd, Livermore MTJ, Bradley DJ, et al. Climate change and future populations at risk of malaria. Glob Environ Change. 1999;9:S89-107.

180. Pascual M, Ahumada JA, Chaves LF, Rodó X, Bouma M. Malaria resurgence in the East African highlands: temperature trends revisited. Proc Natl Acad Sci USA. 2006;103:5829-34.

181. Rogers DJ, Randolph SE. The global spread of malaria in a future, warmer world. Science. 2000;289:1763-6.

182. Yamana TK, Eltahir EAB. Projected impacts of climate change on environmental suitability for malaria transmission in West Africa. Environ Health Perspect. 2013;121:1179-86.

183. IPCC. IPCC 5th assessment report "Climate Change 2013: The Physical Science Basis". Final draft underlying scientific-technical assessment. Stockholm, 23-26 September 2013: Working Group I-12th Session. 2013. http://www.ipcc.ch/report/ar5/wg1/\#.UkveNn_gFTU. Accessed 1 Feb 2016.

184. Takken W, Vilarinhos PTR, Schneider P, Santos F. Effects of environmental change on malaria in the Amazon region of Brazil. In: Takken W, Martens P, Bogers R, editors. Environmental change and malaria risk: global and local implications. Wageningen; 2005. p. 113-23.

185. Paaijmans KP, Blanford S, Bell AS, Blanford JI, Read AF, Thomas MB. Influence of climate on malaria transmission depends on daily temperature variation. Proc Natl Acad Sci USA. 2010;107:15135-9.

186. Tambo E, Ai L, Zhou X, Chen J-H, Hu W, Bergquist R, Guo J-G, Utzinger J, Tanner M, Zhou X-N. Surveillance-response systems: the key to elimination of tropical diseases. Infect Dis Poverty. 2014;3:17.

187. Ohrt C, Roberts KW, Sturrock HJW, Wegbreit J, Lee BY, Gosling RD. Information systems to support surveillance for malaria elimination. Am J Trop Med Hyg. 2015;93:145-52.

188. Martens P, Hall L. Malaria on the move: human population movement and malaria transmission. Emerg Infect Dis. 2000;6:103-9.

189. Prothero RM. Forced movements of population and health hazards in tropical Africa. Int J Epidemiol. 1994;23:657-64.

190. Monte-Mór RL. Modernities in the jungle: extended urbanization in the Brazilian Amazonia. Ph.D., University of California, LA, USA. 2004.

191. Sturrock HJW, Roberts KW, Wegbreit J, Ohrt C, Gosling RD. Tackling imported malaria: an elimination endgame. Am J Trop Med Hyg. 2015;93:139-44.

192. Wangdi K, Gatton ML, Kelly GC, Clements ACA. Cross-border malaria: a major obstacle for malaria elimination. Adv Parasitol. 2015;89:79-107.

193. Pommier de Santi V, Dia A, Adde A, Hyvert G, Galant J, Mazevet M, et al. Malaria in French Guiana linked to illegal gold mining. Emerg Infect Dis. 2016:22:344-6.

194. United Nations. Transforming our world: the 2030 agenda for sustainable development. In: A/RES/70/1. Geneva: United Nations; 2015. p. 41.

195. United Nations Development Programme (UNDP). Multisectoral action framework for malaria. Geneva: United Nations Development Programme (UNDP), Roll Back Malaria Partnership (RBM); 2013. p. 68.

196. Brasil. Portaria no. 1, de 13 de Janeiro de 2014. Secretaria de Vigilância em Saúde. Diário Oficial da União—Seção 1. 2014. p. 4.

197. Cohen J, Smith D, Cotter C, Ward A, Yamey G, Sabot O, et al. Malaria resurgence: a systematic review and assessment of its causes. Malar J. 2012;11:122.

198. Koenker H, Keating J, Alilio M, Acosta A, Lynch M, Nafo-Traore F. Strategic roles for behaviour change communication in a changing malaria landscape. Malar J. 2014;13:1.

199. PAHO, WHO. Report on the status of malaria eradication in the Americas. XIV Report. Washington, DC: Pan American Health Organization, World Health Organization; 1966. 